\title{
Damage and seismic velocity structure of pulverized rocks near the San Andreas Fault
}

\author{
Marieke Rempe, ${ }^{1,2}$ Thomas Mitchell, ${ }^{1,3}$ Jörg Renner, ${ }^{1}$ Stuart Nippress, ${ }^{4,5}$ \\ Yehuda Ben-Zion, ${ }^{6}$ and Thomas Rockwell ${ }^{7}$ \\ Received 20 October 2012; revised 5 April 2013; accepted 5 April 2013; published 28 June 2013.
}

[1] A combination of seismic refraction tomography, laboratory ultrasonic velocity measurements, and microstructural observations was used to study the shallow velocity structure of a strand of the San Andreas fault (SAF) just south of Littlerock, California. The examined site has a strongly asymmetric damage structure with respect to the SAF core. The conglomerates to the southwest show little to no damage, whereas a $\sim 100 \mathrm{~m}$ wide damage zone exists to the northeast with a $\sim 50 \mathrm{~m}$ wide zone of pulverized granite adjacent to the fault core. Seismic P-wave velocities of the damaged and pulverized granite were investigated over a range of scales. In situ seismic velocity imaging was performed on three overlapping profiles normal to the SAF with lengths of $350 \mathrm{~m}, 50 \mathrm{~m}$, and $25 \mathrm{~m}$. In the laboratory, ultrasonic velocities were measured on centimeter- to decimeter-sized samples taken along the in situ profiles. The samples were also investigated microstructurally. Micro-scale fracture damage intensifies with increasing proximity to the fault core, allowing a subdivision of the damage zone into several sections. Laboratory-derived velocities in each section display varying degrees of anisotropy, and combined with microfracture analysis suggest an evolving damage fabric. Pulverized rocks close to the fault exhibit a preferred fault-parallel orientation of microfractures, resulting in the lowest P-wave velocity orientated in fault-perpendicular direction. Closest to the fault, pulverized rocks exhibit a gouge-like fabric that is transitional to the fault core. Comparison of absolute velocities shows a scaling effect from field to laboratory for the intact rocks. A similar scaling effect is absent for the pulverized rocks, suggesting that they are dominated by micro-scale damage. Fault-parallel damage fabrics are consistent with existing models for pulverized-rock generation that predict strong dynamic reductions in fault-normal stress. Our observations provide important constraints for theoretical models and imaging fault damage properties at depth using remote methods.

Citation: Rempe, M., T. Mitchell, J. Renner, S. Nippress, Y. Ben-Zion, and T. Rockwell (2013), Damage and seismic velocity structure of pulverized rocks near the San Andreas Fault, J. Geophys. Res. Solid Earth, 118, 2813-2831, doi:10.1002/jgrb.50184.

\section{Introduction}

[2] Pulverized fault zone rocks from along the San Andreas fault (SAF) and other large displacement faults such as the Arima-Takatsuki Tectonic Line [Mitchell et al., 2011] and North Anatolian fault [Dor et al., 2008] have previously been

\footnotetext{
${ }^{1}$ Institut für Geologie, Mineralogie und Geophysik, Ruhr-Universität Bochum, Bochum, Germany.

${ }^{2}$ Now at Dipartimento di Geoscienze, Università degli Studi di Padova, Padua, Italy.

${ }^{3}$ Now at Istituto Nazionale di Geofisica e Vulcanologia, Roma, Italy.

${ }^{4}$ Earth and Ocean Sciences, University of Liverpool, Liverpool, UK.

${ }^{5}$ Now at AWE Blacknest, UK.

${ }^{6}$ Earth Sciences, University of Southern California, Los Angeles, California, USA.

${ }^{7}$ Geological Sciences, San Diego State University, San Diego, California, USA.

Corresponding author: M. Rempe, Dipartimento di Geoscienze, Università degli Studi di Padova, Padua, Italy. (marieke.rempe@rub.de)

(C)2013. American Geophysical Union. All Rights Reserved. 2169-9313/13/10.1002/jgrb.50184
}

investigated with respect to their distribution and unique physical characteristics [Agosta and Aydin, 2006; Billi and Di Toro, 2008; Brune, 2001; Dor et al., 2006a; Dor et al., 2006b; Rockwell et al., 2009; Wilson et al., 2005]. Unlike typical fault zone rocks, such as cataclasites and breccias that reveal accommodation of deformation by localized shear, grain rolling, and grain size reduction [Blenkinsop, 1991], pulverized rocks are characterized by pervasive micro-scale damage due to fragmentation of grains down to the micron-range while still maintaining the original grain boundaries and rock fabric. Lacking indications for macroscopic shear strain, the fragmentation appears associated with a high density of opening mode microfractures. Such structures have previously been interpreted as a product of dynamic stress fluctuations, hence the occurrence of pulverized fault zone rocks has been associated with earthquake rupture [Brune, 2001; Doan and d'Hour, 2012; Doan and Gary, 2009; Dor et al., 2008; Mitchell et al., 2011; Rockwell et al., 2009; Wilson et al., 2005; Yuan et al., 2011].

[3] If the generating mechanism for the pervasive comminution and pulverization of rock is dynamic loading and/or unloading, the transient stresses, whether tensional 
or compressional, likely constitute heterogeneous modulations of the remote stresses [Di Toro et al., 2005; Poliakov et al., 2002; Rice et al., 2005] that may result in anisotropic damage. Therefore, the analysis of pulverized-rock fabrics may help shed light on the dynamic stress fields generated by coseismic processes. While several qualitative and semi-quantitative studies exist on the occurrence of outcrops of pulverized rocks and variations in damage intensity as a function of distance from the fault, a systematic analysis of the variation of damage fabric and anisotropy has not been conducted to date, in part likely due to the difficulty in sampling such fragile rocks. In addition, little is known about the seismic velocity structure of such rocks though this type of information has two intimately linked merits. First, a basic understanding of the seismic structure of fault zones with pulverized rocks constrains the interpretation of seismic images of faults at depth gained from large scale surveys. Second, the variation of damage with spatial scale can be investigated when velocity measurements are performed at a range of wavelengths.

[4] In this integrated study, we examine the shallow velocity structure of a fault strand in the Mojave section of the SAF just south of Littlerock, California, by combining seismic refraction tomography, laboratory measurements of ultrasonic velocity, and microstructural observations in order to characterize the macro- and micro-scale structure of the pulverized rocks close to the surface. The combination of field- and laboratory-scale velocity measurements allows us to address the intrinsic scale dependence of seismic velocities and examine velocity anisotropy in relation to fracture damage. It may be hypothesized that the seismic velocity will show limited scale sensitivity as pulverized rocks exhibit a tendency for pervasive micro-scale damage and an apparent lack of macroscopic velocity-reducing features, such as faults and fractures [e.g., Pierre et al., 2012; Stierman and Kovach, 1979; Trippetta et al., 2010]. A potential absence of scale dependence becomes important when interpreting larger scale seismic data that address fault structure at depth using large wavelengths by necessity.

[5] In the following, we first describe the general geology of the Littlerock site. Then, we introduce the employed methods for sample collection and seismic refraction tomography. After presenting results of microstructural analysis, velocity measurements on laboratory- and refraction-survey scale, we discuss the relationship between damage structure and velocity, velocity scaling, and effects of small-scale anisotropy on larger-scale tomographic models. We conclude by discussing implications for damage generating mechanisms and routes for further work.

\section{Geology, Fault Structure, and Field Methods}

\subsection{Structural Overview of the Mojave Section of the SAF}

[6] The SAF system in the Mojave section consists of several subparallel fault strands located on the northern slope of the San Gabriel Mountains (Figures 1a and 1b), with the San Gabriel fault within the ranges to the south [Barrows et al., 1985]. Faulting along the northern slope of the San Gabriel Mountains originated 4.5 to $5 \mathrm{~m}$.y. ago. The currently active trace of the SAF, referred to hereon as the SAF trace, was formed in the Pleistocene less than $1 \mathrm{~m}$. y. ago [Barrows et al., 1985] and accommodated a minimum of $21 \mathrm{~km}$ of right lateral displacement. It hosted the last great earthquake in southern California, the Mw7.9 1857 Fort Tejon earthquake, and the study site is located on this strand. The SAF trace was preceded by several subsidiary ancestral faults, including the Little Rock fault, the Punchbowl fault, and the Nadeau set of faults (Figures 1a and 1b), which developed sequentially until they were finally abandoned [Barrows et al., 1985; Powell and Weldon, 1992]. Despite the ancestral traces having been bypassed, they still exist as zones of weakness which have been reactivated in the Quaternary and accommodate minor dip-slip displacement [Barrows et al., 1985]. Such movement has resulted in the formation of fault scarps that are often separated by sections of Holocene fluvial deposits along the faults (Figure 2a).

[7] In the historical sequence of strand formation and activity, the Punchbowl fault formed after the deposition of the Punchbowl Formation in Hemphillian time ( $\sim 5$ m.y. ago), and hosted about $44 \mathrm{~km}$ of right lateral displacement. Detailed studies of the Punchbowl fault revealed a localized fault core tens of $\mathrm{cm}$ thick accommodating the bulk of total displacement, surrounded by a fracture damage zone up to $100 \mathrm{~m}$ in width [Chester et al., 2004; Chester and Logan, 1986; Wilson et al., 2003]. The Little Rock fault, formed after deposition of the Anaverde Formation (shales and siltstones) in Hemphillian time ( 4.5 to 5 m.y. ago), accommodated $21 \mathrm{~km}$ of right lateral displacement [Barrows et al., 1985], similar to the displacement on the currently active trace. The Nadeau fault formed after the deposition of the Juniper Hills Formation, inferred to be approximately Plio-Pleistocene age (2.5 m.y. or younger), and experienced about $16 \mathrm{~km}$ of right lateral displacement. Thus, including the San Gabriel fault to the south, the cumulative displacement since the Pliocene is around $162 \mathrm{~km}$ [Barrows et al., 1985]. Based on offset geological units [Dibblee, 1989] from Miocene and older, however, the total displacement on the SAF in southern California amounts to more than $300 \mathrm{~km}$. The discrepancy suggests that nearly half of the SAF slip occurred prior to the Pliocene [c.f. Powell, 1993] or that several other smaller scale faults exist between these major faults but are not mapped due to a lack of exposure.

\subsection{Pulverized Rocks in the Mojave and the Littlerock Paleoseismic Site}

[8] Only in recent years have pulverized rocks been reported along various sections of the SAF [Brune, 2001; Dor et al., 2006a; Dor et al., 2009; Dor et al., 2006b; Rockwell et al., 2009; Wilson et al., 2005], farther to the north on the Garlock fault [Rockwell et al., 2009], and to the west on the San Jacinto fault [Rockwell et al., 2009; Wechsler et al., 2009]. Dor et al. [2006a] presented a systematic study of all exposed outcrops of pulverized rock over a $140 \mathrm{~km}$ stretch of the Mojave segment of the SAF, including the segment of the SAF shown in Figure 1a. They showed that almost every outcrop of crystalline rock close to the fault is pulverized without significant macroscopic shear, and that $70 \%$ of the pulverized rock appears on the northeast side of the principal slip zone of the SAF, reflecting an asymmetric structure of the damage zone. Some examples of pulverization in sedimentary rocks were observed, and were mostly located on the northeast side of the SAF. Our field survey and sample collection were conducted at the Littlerock Paleoseismic Site, located in the vicinity of $96^{\text {th }}$ Street East, south of the 


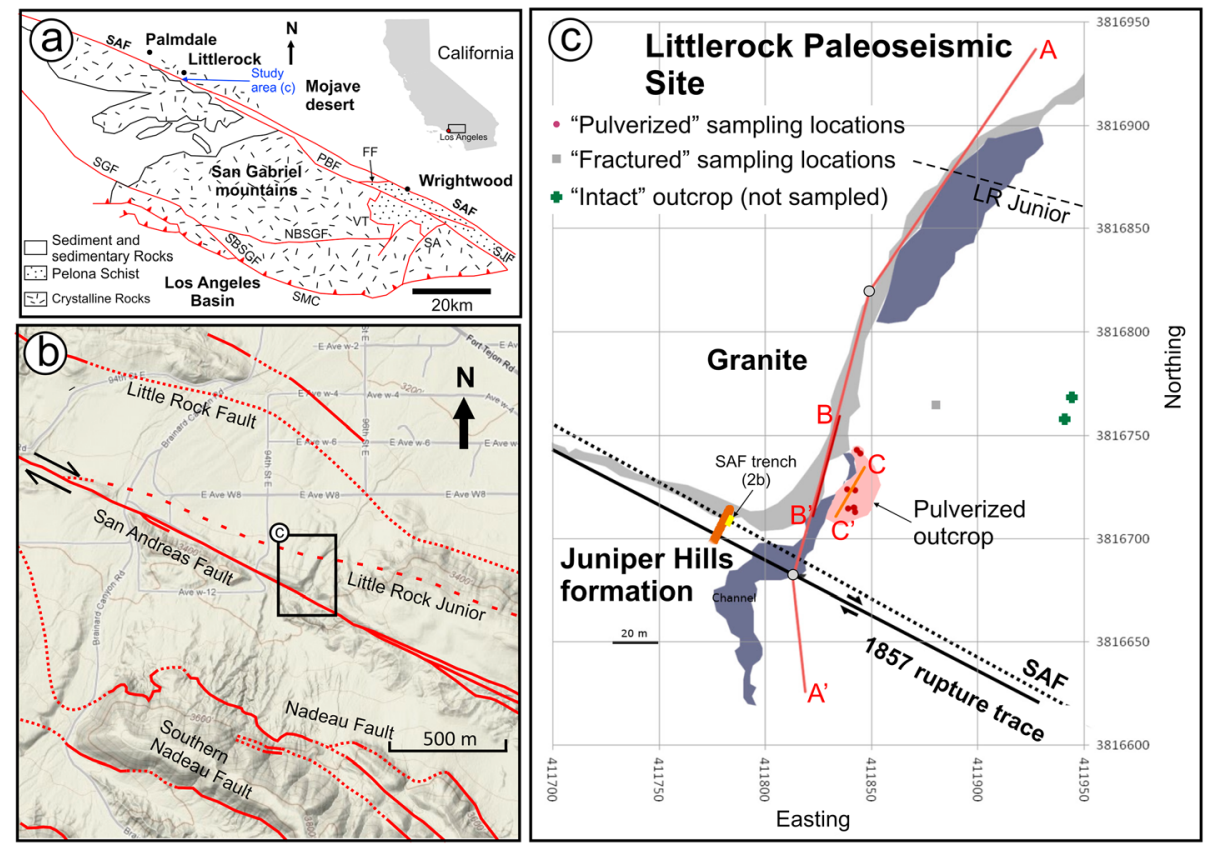

Figure 1. (a) Region surrounding the study area in southern California (see inset) showing major tectonic and geologic elements. Modified from Schulz and Evans [2000]. Major faults are labeled: SAF: San Andreas fault, PBF: Punchbowl fault, SGF: San Gabriel fault, NBSGF: north branch of the San Gabriel fault, SBSGF: south branch of the San Gabriel fault, SMC: Sierra Madre-Cucamonga fault, SA: San Antonio fault, FF: Fenner fault, SJF: San Jacinto fault. (b) Fault map of the San Andreas fault and other nearby faults south of the town of Littlerock, Southern California. Faults are taken from 1:12,000 fault map of the west half of the Juniper Hills segment of the San Andreas fault in Barrows et al. [1985]. Wide-spacing dashed line denotes the location of a new fault inferred in this study. (c) Map of the Littlerock Paleoseismic Site, southern California, showing basic geologic and morphologic features of the study site. The dotted line represents the long-term SAF trace, and the solid line the 1857 rupture trace and currently active strand. The newly inferred LR Junior fault is represented by a long-dashed line. The position of the trench made by Schwartz and Weldon [1986] and re-trenched by Dor et al. [2006b] is indicated by dark orange bar with the yellow mark showing position of Figure 2b. Lines A-A', B-B', and C-C' represent seismic profiles $\mathrm{A}, \mathrm{B}$, and $\mathrm{C}$, respectively; red and gray dots show sampling locations and locations of macroscopically intact granite outcrops. The dark gray area marks the dry river's main wash, the blue a secondary channel that shows deflection by fault offset, and the pink the pulverized-rock outcrop.

town of Littlerock, CA (Figures $1 \mathrm{~b}$ and 1c), one of the various outcrops of pulverized granitic rock along the SAF identified by Dor et al. [2006a]. This site provides some of the best exposures of pulverized rocks in the Mojave segment and is well suited for a seismic refraction study because of its relatively flat topography resulting from faultperpendicular stream incision.

[9] At the Littlerock Paleoseismic site, the SAF juxtaposes Cretaceous granite to the northeast against sandstones of the conglomeratic late-Pliocene Juniper Hills Formation to the southwest, both overlain by middle Holocene $(3.5 \mathrm{ka})$ unconsolidated alluvial deposits [Dor et al., 2006b]. Previous investigations by excavation of trenches exposed fault details [Schwartz and Weldon, 1986; Weldon and Fumal, 2005]. The fault is actually composed of two nearby strands [Dor et al., 2006b], the post-middle Pleistocene long-term SAF trace in the area that accommodated the 19 to $21 \mathrm{~km}$ of right lateral displacement [Barrows et al., 1985] and the 1857 rupture trace located 5 to $8 \mathrm{~m}$ to the south (Figures $1 \mathrm{c}$ and 2a), likely to be the shallow surface expression of the SAF trace. Fault trenches made normal to the long-term trace reveal a fault core up to $50 \mathrm{~cm}$ wide consisting of fine-grained clay-rich fault gouge
(Figure 2b) and a principal slip surface on the southwest edge dipping about $60^{\circ}$ to the southwest [Dor et al., 2006b]. Dor et al. [2006b] described the fault zone layer to the north of the principal slip surface, with an appearance intermediate between a typical gouge and the granitic wall rock, as "proto-gouge", which lies solely within the granitic unit.

[10] The Juniper Hills Formation was never deeply buried during the activity of the dominantly strike-slip fault [Dor et al., 2006b], and thus the structure of these rocks is a result of the fault activity. As paleoseismic studies on this strand of the SAF have shown evidence for large seismic events over the last 6000 years [Weldon and Fumal, 2005], it can be assumed that such seismicity occurred over much of the displacement history of the Juniper Hills Formation [Dor et al., 2006b] and that any damage, or lack thereof, is associated with slip events. In the study area, the Juniper Hills sediments directly to the southwest of the fault traces were previously found to be macroscopically undamaged [Dor et al., 2006a]. Examples of cm-scale conglomeratic pebbles close to the fault trace display no indication of mesoscopic fracture damage and thus indicate an asymmetric damage structure with respect to the slip zone [Dor et al., 2006b]. 

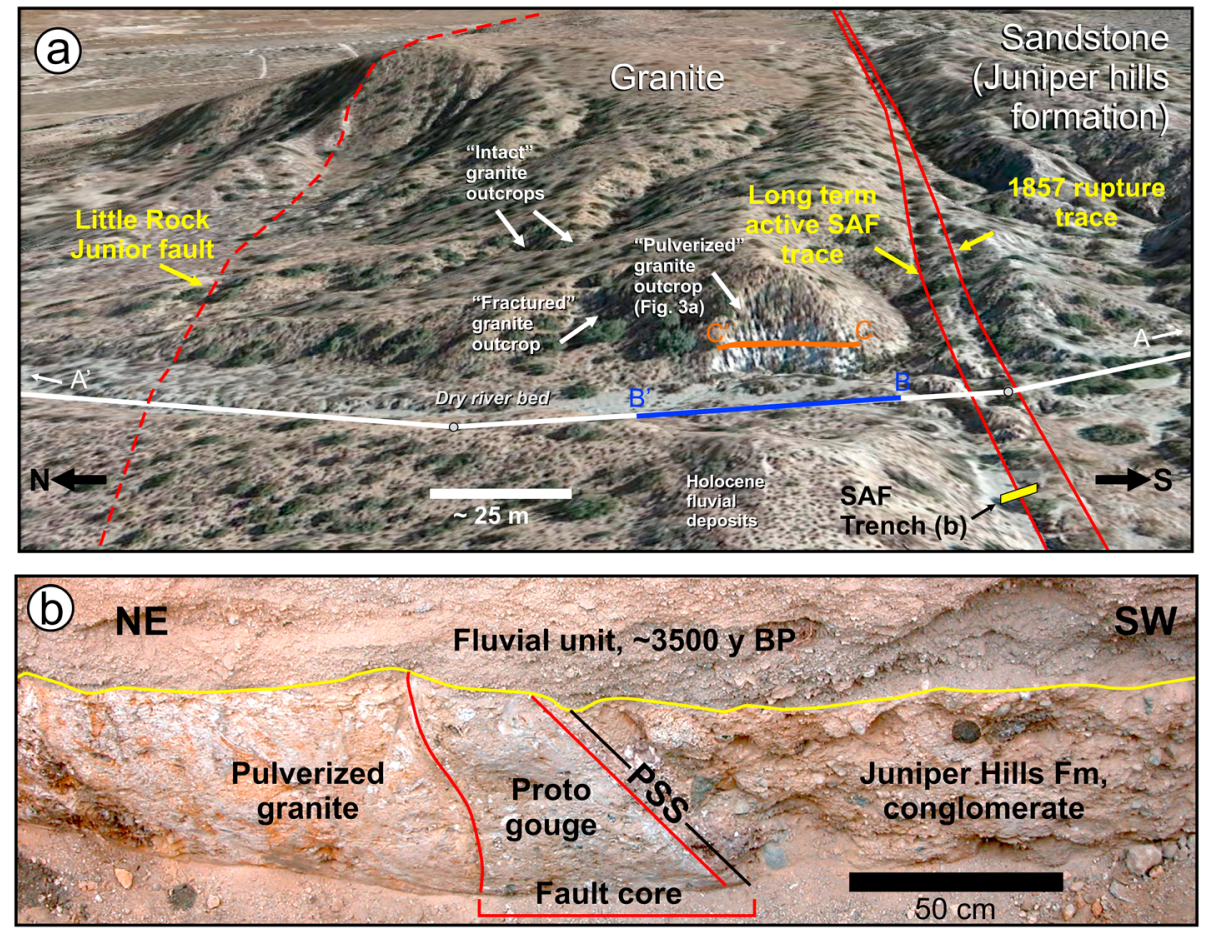

Figure 2. (a) Google Earth 3D image of the study area looking southeast along the San Andreas fault. Major faults, outcrop locations and seismic profile lines are overlain. (b) The trench exposure of Dor et al. [2006] (yellow box in Figure 2a above) exposing the core of the SAF long-term trace, modified from Dor et al. [2006], exhibiting the asymmetrical damage structure of the fault zone. The fault core separates the Juniper Hills Fm. and the pulverized granite, and consists of a proto-gouge zone 40 to $50 \mathrm{~cm}$ in thickness with a $5 \mathrm{~cm}$ thick principal slip surface (PSS) to the southeast.

However, a few locations mapped by Dor et al. [2009] to the east of the Littlerock Paleoseismic site do show examples of highly microfractured rocks of the Juniper Hills conglomerates.

\subsection{Field Methods}

\subsubsection{Sample Collection}

[11] While exposures are limited at the Littlerock site due to the cover consisting of Holocene fluvial deposits, several outcrops of granite with varying levels of damage can be found northeast of the fault traces (Figures 1c and 2a): (a) a pulverized-rock outcrop (50 to $20 \mathrm{~m}$ from the SAF trace (Figure 3a), (b) outcrops of macroscopically fractured granite (70 to $60 \mathrm{~m}$ from the trace), and (c) two small outcrops of relatively intact granite ( $\sim 105$ to $95 \mathrm{~m}$ from the trace). The exposed granite consists of quartz, K-feldspar, and plagioclase, with muscovite and minor biotite, and is of yellowish-white color. The pulverized variety has a powder-like texture when crushed in the hand, but with some phenocrysts still distinguishable (Figures $3 \mathrm{~b}, 3 \mathrm{c}$, and 3d). At hand specimen-scale, the pulverized rock shows no obvious variations in intensity of damage throughout the majority of the exposure. Macroscopic features are lacking and damage is limited to the grain-scale. Toward the north end of the $30 \mathrm{~m}$ wide outcrop (Figure 3a), however, the pulverized rock is more cohesively judged from the ease of sampling suggesting a lesser degree of pulverization.

[12] The intention of sample collection was to compare laboratory-derived velocities of pulverized rocks with in situ seismic refraction velocities, and investigate velocity anisotropy in the light of microstructural observations. Pulverized rocks are particularly difficult to sample, owing to their friable nature, and thus specific sampling and preparation techniques were employed in order to preserve the rock fabric without introducing additional damage. We discussed the question of relying on standard two-component resin as used in preparation shops or alternatives for fixation of samples in situ. The field experience showed that inexpensive wood glue from a local hardware store serves the purpose well. The chosen glue probably reduces setting time over resin and avoids the necessity of mixing components. Oriented samples of pulverized rock were collected by pouring the liquid wood glue onto selected rock outcrops in situ and by subsequently carving carefully around the sample after several hours, once the glue had set. Each excavated rock sample with a size of about 10 by $10 \mathrm{~cm}$ was then wrapped in duct tape and orientation marks placed on the tape. Samples were transported in plastic buckets surrounded by quickset insulation spray-foam to prevent damage in transit. Oriented samples of in situ intact rock could not be collected from the Littlerock site due to proprietary issues, and so for comparison to the more damaged rock we rely on a loose sample collected nearby at the surface with a mineral inventory comparable to the moderately fractured rock. Details of sample preparation, determination of ultrasonic velocities, and bulk densities, and estimation of microfracture orientation and density are given in the appendix.

\subsubsection{Seismic Refraction Experiment and Tomographic Inversion}

[13] Three seismic refraction profiles were conducted perpendicular to the fault traces in the vicinity of the outcrop of 

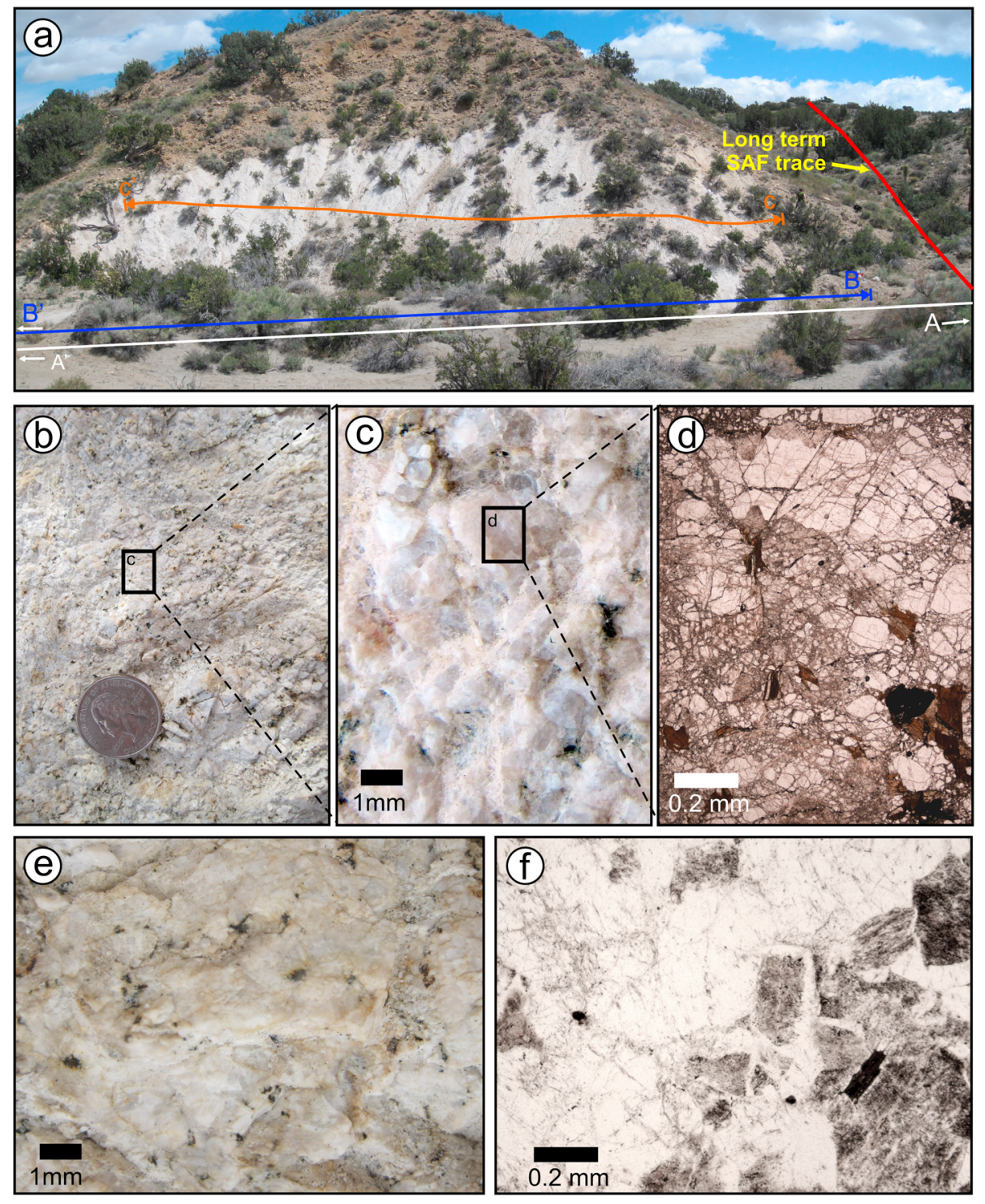

Figure 3. (a) Field picture of pulverized-rock outcrop, clearly identifiable by its white color, with location of seismic profiles and the long-term SAF trace marked in red. For scale, note that transect $\mathrm{C}$ is $25 \mathrm{~m}$ long. (b) The pulverized rock around $30 \mathrm{~m}$ from the long-term SAF trace has a powdery, friable texture. In magnification (c), it is possible to identify the original igneous texture, with individual phenocrysts distinguishable. (d) Thin section image showing a typical microstructure: high density of microfractures, angular grains, and a lack of significant shear. (e) Granite about $100 \mathrm{~m}$ from the SAF trace with macroscopically intact texture. (f) Transmitted light thin section of intact granite.

pulverized rocks at Littlerock site (Figures 1c, 2a, and 3a). The design of the profiles was chosen to provide coverage for an intermediate-scale $(>100 \mathrm{~m})$ investigation into the relation between subsurface velocity and distance to the fault, as well as to potentially constrain meter-scale structural variability of a pulverized-rock unit. Profile $A$ was $350 \mathrm{~m}$ long and located along a dry river bed that is offset by the SAF (Figures 1c and 2a). While most of its length covers the northeast side of the SAF, an approximately $50 \mathrm{~m}$ long stretch extends over to the southwest side (Figure 1c). On either side of the fault, the two rock types that were documented from previous trenches, pulverized granite, and sandstone, are covered by fluvial sediments, loose gravel, and sand. The 72 geophones used were simply pushed into the alluvial sand spaced at $5 \mathrm{~m}$ and covered with loose rocks to reduce the noise due to wind. Profile $B$ was $50 \mathrm{~m}$ long covering the section of profile A where pulverized rocks actually crop out about $10 \mathrm{~m}$ from the dry river bed. The 24 geophones were buried between 0.4 and $0.9 \mathrm{~m}$ deep at a spacing of $2 \mathrm{~m}$. The holes' depth was controlled by the interface between alluvial sediments and the upper weathered layer of bedrock, into which the geophones were pressed. The depths down from the surface to the buried geophones were measured to determine the true vertical elevation of individual geophones. Profile $C$ was $25 \mathrm{~m}$ long using 48 geophones spaced $0.5 \mathrm{~m}$ apart on the outcrop of pulverized rock about $10 \mathrm{~m}$ offset to the east from profiles A and B. After scraping away loose surface debris, geophones were again simply placed directly into weathered pulverized rock and covered with loose rock. 
[14] The seismic source was a sledge hammer with a weight of $5 \mathrm{~kg}$. Source locations were equidistant between each pair of neighboring geophones. At each location, 10 hammer strikes to a steel plate were recorded and stacked using a Geometrics 24-channel Geode. ReflexW (CSandmeier Scientific Software 2011) was used for simple preprocessing and first breaks were picked with an uncertainty ranging between 1 and $5 \mathrm{~ms}$. In total, we determined 900 first breaks for profile A, 507 for profile B, and 1126 for profile C.

[15] The 2D regularized inversion algorithm FAST [Zelt and Barton, 1998] was used to derive velocity models for each of the profiles using first break arrivals. The algorithm was modified following the procedure outlined by Ryberg et al. [2007] to reduce the dependence of the final velocity model on the starting model. Initially, we used a 1D starting model derived from the analysis of time distance plots of the picked first breaks and inverted for a coarse 2D model. The inversion result was then used as a starting model to invert iteratively for a finer model until the traveltime misfit between model and data either reached the picking error or was a minimum, and the horizontal block size is no smaller than half of the geophone spacing.

[16] Interpretation of tomographic models requires an understanding of their spatial resolution. We performed two tests. First, we plotted the ray coverage as an initial proxy to resolution. Areas with dense ray coverage should be well resolved compared to areas of sparse ray coverage. Second, a checker-board test was performed to determine the spatial resolution of our inversion. Rectangular velocity anomalies $( \pm 5 \%$ velocity perturbation) were overlaid over a starting model, a strongly smoothed version of the final velocity model for each profile. Synthetic traveltimes were calculated along similar ray paths as those used in our tomographic inversion. A $\pm 10 \mathrm{~ms}$ random noise (corresponding to 2 to 10 times the picking error) was added to the synthetic traveltime data before inversion. Areas of the inverted model that recreate the initial checker-board (both in amplitude and shape) are well resolved. Diminished amplitudes of the velocity perturbations suggest that the model is not completely resolved and that the seismic velocities in our tomographic model are not the true in situ velocities. A smearing out of the checker-board also suggests that any features in the tomographic model will be smeared in contrast to actual subsurface structure. Finally, for every ray, we calculated the angle (from the horizontal) that it traversed each of the model blocks to gain mean ray angles for each block.

\section{Results}

[17] In the following, the damage observations from the field and the microstructural investigation are introduced and linked. Then, we present the results from the laboratory measurements. Finally, the in situ velocity profiles are shown, also addressing their spatial resolution.

\subsection{Field and Microstructural Damage Observations}

[18] Observations on polished thin sections cut parallel and perpendicular to the main SAF trace by transmitted light microscopy show a systematic correlation of microstructures with distance from the fault core (Figures 4 and 5) and lead us to divide the fault rocks into four groups according to their damage states; (1) "intact", (2) "fractured", (3) "pulverized", and (4) "pulverized and sheared", with units (2), (3), and (4) constituting the damage zone of the SAF:

[19] "Intact". The intact outcrops at distances of 105 to $95 \mathrm{~m}$ show undamaged granitic protolith. The collected intact sample exhibits minimal microfracture damage (Figure 6, sample 1). Microfracture density is the lowest of all samples, and fracture traces lack a preferred orientation, although we can only compare relatively between the two sections orientated perpendicular to each other as this sample was not orientated relative to the SAF.

[20] "Fractured". Between 100 and $50 \mathrm{~m}$ from the SAF trace, fractured rocks (e.g., Figure 6, sample 2) exhibit a relative increase in microfracture damage with increasing proximity to the fault. A slight preference of horizontal fracture traces in the fault-parallel sections and steeply dipping traces in the perpendicular section indicate a preference for northwest-southeast striking subparallel fractures, with a relatively steep northeast dip direction away from the fault. Fractures are generally closed, with minor shear offset of grain boundaries by some of the larger intergranular fractures, although no particular orientation appears to show a preference for shear.

[21] "Pulverized". The transition from "fractured" to "pulverized" rock occurs at around $50 \mathrm{~m}$ from the SAF trace, with a significant increase in microfracture density. Damage intensity in the pulverized rocks suffices to reduce cohesion significantly and samples are extremely friable (Figure 6, samples 3 and 4). Fragility and reduced cohesion are key macroscopic characteristics that differentiate pulverized rock from the fractured rock. The cm-scale thin section scan of sample 3 shows the intense degree of microfracturing, but original grain boundaries can still be identified. All sections in the pulverized zone display extensive evidence of in situ shattering within the crystalline components of the granite, and residual angular fragments as small as $50 \mu \mathrm{m}$. In sample 3, a preference for vertically orientated fracture traces in the fault-parallel section and steeply dipping traces in the fault-perpendicular section suggests that microfractures are preferentially vertically orientated, but their strike cannot be deduced without a third (horizontal) section. Sample 4 shows a distinct increase in microfracture density relative to sample 3 , also with a preference for vertically orientated fractures again without specifiable strike. However, sample 4 exhibits fracture traces (arrowed in yellow in Figure 6), which appear to be more open relative to other, thinner, traces in these thin section planes. These open fracture traces have a slightly inclined, subvertical orientation in the faultperpendicular section. In the fault-parallel section, traces are horizontal to subhorizontal and generally have a wider apparent aperture than those in the fault-perpendicular sections. Identification of any systematic crosscutting or other timing relationships of fractures is difficult, as the majority shows no evidence of shear.

[22] "Pulverized and Sheared". The boundary from "pulverized" to "pulverized and sheared" rock is transitional, occurring between 30 and $0 \mathrm{~m}$ from the SAF trace. Discrete zones of shearing are evidenced by the offset of grain boundaries, grain rotation, and rounded grains, as most clearly seen in the cm-scale thin section scans of samples 5 and 6 (Figure 6). Localized bands of more intensely pulverized rock contain 

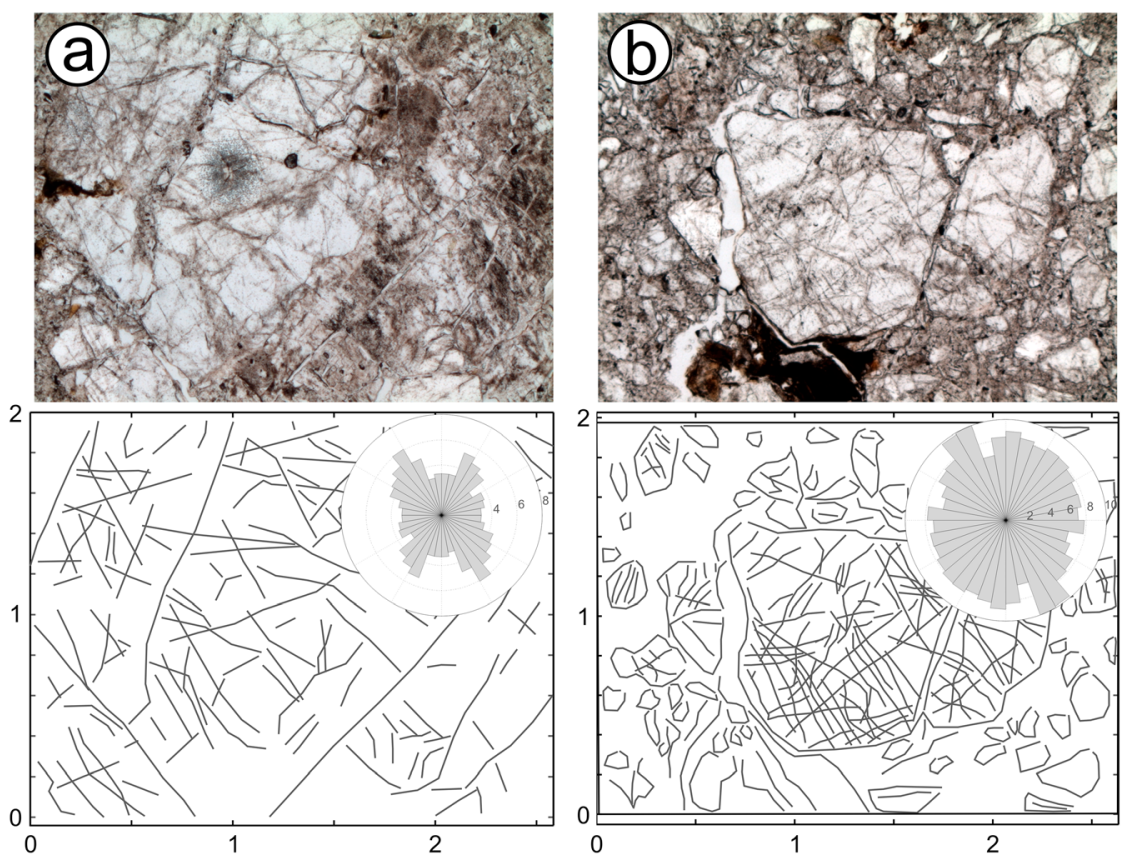

Figure 4. Examples of plane polarized light microphotographs and digital maps of fracture traces for samples of (a) "fractured" and (b) "pulverized" rock. Digital maps were used to measure microfracture orientation and the resulting rose diagram. The rose diagrams are scaled to the square root of the measurement frequency, so that areas in the diagrams are proportional to frequency [Griffith et al., 2010]. (b) In the digital trace of sample 4 (see also Figure 6), the outermost regions of the microphotograph surrounding the large grain have no traced fractures because the pulverized particles, while representative of high damage intensity, are of too small scale to be traced.

finer-grained particles and in some cases rounded clasts (arrowed, Figure 6, sample 5). Microfracture density is still relatively high, but slightly decreased in comparison to the pulverized sample (5), as is the magnitude of the anisotropy in the fracture-trace orientations. In part, the reduction in fracture density is due to the fact that in the more pulverized samples, fractures cannot be identified in regions where the small size of the fragments is below the resolution of the images (Figure 4b). Rocks closest to the fault trace show a progression to more extensive shearing and comminution (Figure 6, sample 6). Cataclasis and brecciation processes appear to have resulted in comminution to fine-grained particles, and a moderate fault-parallel fabric defined by subtle variations in grain size and banding of color, where long axes of the angular grains aligned parallel to the fabric is indicated by the three orthogonal $1 \mathrm{~cm}$-scale images in sample 6. Microfracture density is apparently lower due to the resolution tracing issue, and it is difficult to interpret the fracture-trace orientation data due to the grain size reduction. However, some patches of nonsheared highly pulverized rock, in between localized sheared bands (Figure 5, "pulverized and sheared", Figure 6, sample 6 fault-parallel) still exist, with some examples of shear bands offsetting open fractures and original grain boundaries by several $\mathrm{mm}$, indicating in places that the shearing postdates some of the dilatational fractures. Throughout the pulverized zone, macroscopic faults or joints are lacking.

\subsection{Laboratory Measurements}

[23] We determined a density ranging between 1600 and $2200 \mathrm{~kg} / \mathrm{m}^{3}$ for samples retrieved from all units within the damage zone when determined with the modified wax-clod method (see Appendix C). We also measured the density by Archimedes' method for one of these samples and found a value somewhat less than 2400 instead of $2100 \mathrm{~kg} / \mathrm{m}^{3}$ as gained from the wax-clod method. These two values likely bracket the true mass density and give an indication of the uncertainty involved in the two methods, which is hard to quantify more specifically for these particular samples. The wax-clod method underestimates true density due to excessive apparent porosity enclosed between the silicon layer and the sample. In contrast, Archimedes' method overestimates true density due to some imbibition when submerging the sample in water. For the granite sample collected at the surface from within our study area that has the same mineral composition as samples of fractured rock and that we consider representative of relatively intact granite, the geometrically determined density was $2610 \mathrm{~kg} / \mathrm{m}^{3}$.

[24] The preparation procedure enabled us to measure ultrasonic velocities of the rocks in directions perpendicular and parallel to the fault as well as in the vertical direction. Measured ultrasonic velocity of the nominal intact granite sample is about $4000 \mathrm{~m} / \mathrm{s}$ and exhibits a modest directional dependence, as shown by the range in velocities that was obtained from the three orthogonal directions (green box in Figure 7). The intact sandstone sample yields velocities that fall right into the range of velocities of 1000 to $3000 \mathrm{~m} / \mathrm{s}$ determined for granitic samples retrieved from the damage zone outcrops. The anisotropy of wave speed in the sandstone is modest, too. The damage zone samples, including the "fractured", "pulverized", and "pulverized and sheared" rocks (Figures 5 and 6), show varying degrees of directional anisotropy. The horizontal velocity 
Intact granite

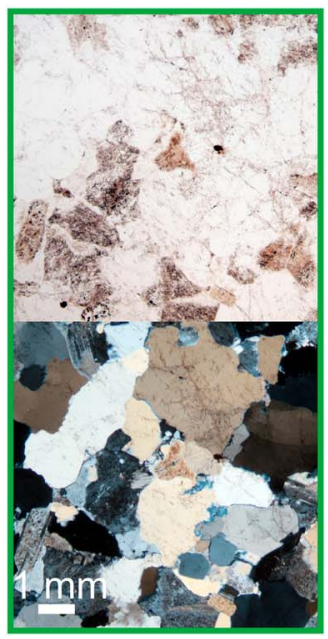

Fractured

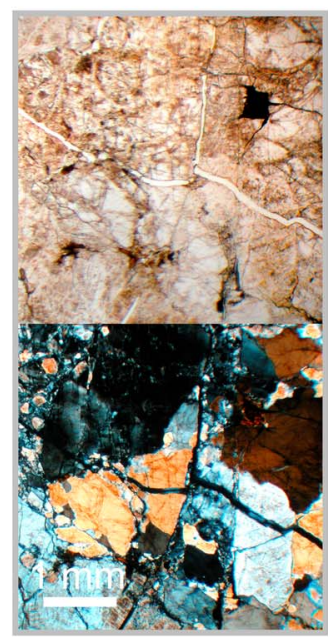

Pulverized

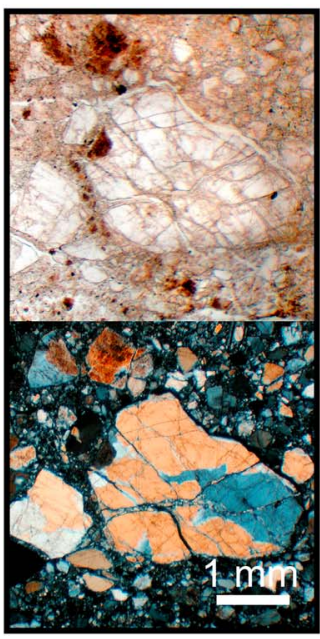

Pulverized

\& sheared

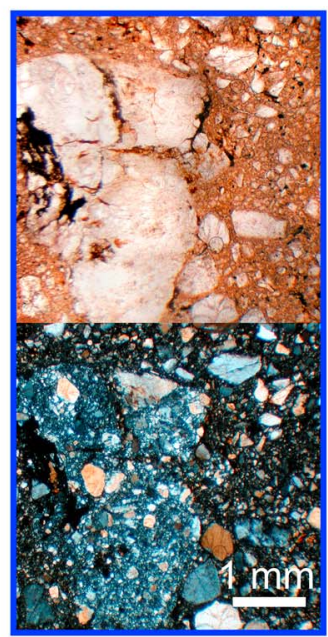

Figure 5. Plane polarized and crossed polarized transmitted light images featuring representative microstructures of four main units of granitic rock at the Littlerock site: "intact" (green frames), "fractured" (gray), "pulverized" (black), and "pulverized and sheared" (blue) in order of increasing degree of microfracturing.

normal to the fault is overall the lowest, and anisotropy factors relative to this direction range from 0.7 to 2 with the largest anisotropy found in the "pulverized and sheared" unit closest to the SAF trace.

[25] At a given distance from the fault, sample to sample variation significantly exceeds experimental uncertainty in absolute velocity (Figure 7a). However, an increase in velocity with increasing proximity to the fault may be inferred within the damage zone. Sample to sample variability may to a substantial degree result from the significant dependence of velocity on sample loading (and associated hysteresis) since axial load was generally not precisely controlled during measurements. Yet, we systematically increased the axial load with which the transducers were pressed onto the sample in steps for two rather friable pulverized samples (Figure 7b, pulverized sample). Velocity values almost double from 1000 to $2000 \mathrm{~m} / \mathrm{s}$ over the range of explored loading corresponding to an overburden of roughly 10 to $50 \mathrm{~m}$. We found that for lower loads, transmitted signals become too small to be recorded with our equipment. In comparison to pulverized rocks, the ultrasonic velocities of intact granite sample reveal a modest sensitivity to loading (Figure 7b). The axial loads can only approximately be converted to stress due to the irregular shape of the samples. Better-characterized measurements would only be possible on samples prepared to stricter geometrical specifications. Yet, such a procedure is not an option due to the friable nature of the samples. Results would be substantially biased to samples strong enough to survive preparation. Though all samples supposedly have similar composition, we find a trend of velocity increasing with mass density. For an absence of compositional variations, this correlation indicates that the magnitude of velocity is controlled by the fracture inventory. Yet, we refrain from correlating densities and velocities in closer detail given the uncertainties associated with the measurements.

[26] To rule out an effect of chemical weathering on the observed velocities, the Chemical Index of Alteration
(CIA) [Morton et al., 2012; Nesbitt and Young, 1982] was determined for samples taken from the pulverized-rock outcrop. This index represents the ratio of the molar proportions of aluminum to calcium, potassium, and sodium oxides. As chemical weathering leads to a loss of $\mathrm{Ca}^{2+}, \mathrm{K}^{+}$, and $\mathrm{Na}^{+}$, the CIA offers a good quantitative measure of the degree of weathering. Chemically unaltered granites have CIA values ranging between 45 and 55 . The CIA determined for samples from distances of $\sim 40,50$, and $70 \mathrm{~m}$ from the fault by X-ray fluorescence measurements varies only slightly, with values of 49.3, 50.8, and 50.2, respectively, falling right into the range of unaltered granitic rock. Thus, the observed velocity variations and interpretations likely are not biased by different degrees of weathering.

\subsection{In Situ Velocity Profiles}

[27] The derived tomography models constrain velocity values in blocks of 2 by $1 \mathrm{~m}$ (i.e., horizontal by vertical dimension), 0.6 by $0.3 \mathrm{~m}$, and 0.2 by $0.1 \mathrm{~m}$ for profiles $\mathrm{A}$, $\mathrm{B}$, and $\mathrm{C}$, respectively (Figure 8 ). Velocity values of the models range from $200 \mathrm{~m} / \mathrm{s}$ to $>3000 \mathrm{~m} / \mathrm{s}$. The inverted models are characterized by root mean square misfits of traveltime $\left(\delta t_{\mathrm{RMS}}=\sqrt{\sum\left(t_{i}-t_{i}^{m}\right)^{2}} / N\right)$ and of normalized misfits $\left(\chi^{2}=\sum\left[\left(t_{i}-t_{i}^{m}\right) / \delta t_{i}\right]^{2} / N\right.$, [see Bevington, 1969]) of $9 \mathrm{~ms}$ and 1.3 (profile A), $6 \mathrm{~ms}$ and 1.4 (profile B), and $10 \mathrm{~ms}$ and 1.8 (profile $\mathrm{C}$ ), respectively. Ideally the modeling would reach $\delta t_{\mathrm{RMS}} \leq \overline{\delta t}$ and $\chi^{2} \approx 1$. Here, the differences between picked traveltimes $t_{i}$ and modeled traveltimes $t_{i}^{m}$ systematically exceed the uncertainty of first breaks, $\delta t=1$ to $5 \mathrm{~ms}$, likely due to three-dimensional structure and/or significant contribution by anisotropy, neither of which can be modeled in our two-dimensional isotropic approach.

[28] For profile B, both the ray density and ray angle plots show that the majority of the rays travel horizontally at the base of the surficial low velocity zone (Figure 9). Both the velocities and vertical features are well resolved. For profile 

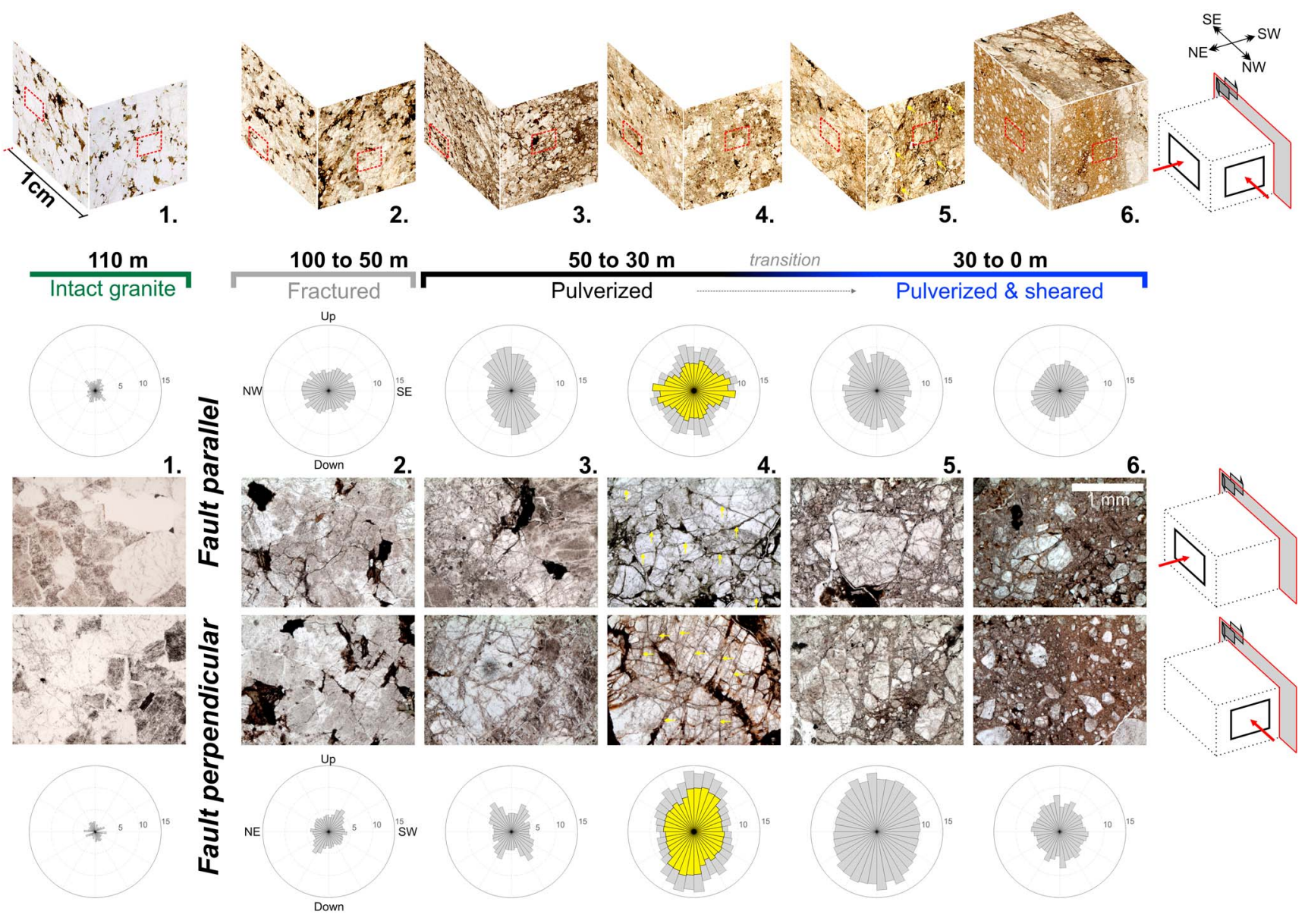

4.

50 to $30 \mathrm{~m}$

transition

6.

Figure 6. Evolving microstructure throughout fault zone at Littlerock Paleoseismic site shown by micrographs of samples from "intact", "fractured", "pulverized", and "pulverized and sheared" zones and the corresponding rose diagrams depicting degree of microfracturing and the fracture orientations. The top row shows high-resolution transmitted light scans of the thin sections, with the approximate locations of the smaller-scale photomicrographs below. Thin sections are orientated fault-parallel and perpendicular, as shown by the schematic to the right. Yellow arrows indicate localized bands of shear in the top row for sample 5, and opening mode fractures in the lower rows of sample 4 . The orientation of those open fracture traces is plotted in yellow in the rose diagram. Note intact sample 1 was not in situ, and therefore orientation data cannot be compared to samples 2 to 6 .

A, the majority of the rays travel in the center of the profile $(-200 \mathrm{~m}$ to $-50 \mathrm{~m})$ where the checkerboard tests show good resolution (Figure 10). Toward either end of the profile, velocities appear diminished but there the checkerboard pattern is smeared out and resolution is low. The ray angle plot shows two main depths with predominately horizontally travelling rays at $\sim 1000 \mathrm{~m}$ and $\sim 985 \mathrm{~m}$.

[29] The velocities imaged in the three tomographic models closely agree in regions where they sample the same substratum. The models display a homogeneous top layer characterized by low velocities that linearly increase with depth from $\sim 200 \mathrm{~m} / \mathrm{s}$ to $\sim 1000 \mathrm{~m} / \mathrm{s}$ (Figure 8 ). The thickness of this layer is the largest for profile $\mathrm{A}$, ranging from 5 to $12 \mathrm{~m}$. For the other two profiles, the thickness is lower with 1.5 to $5 \mathrm{~m}$ for profile $\mathrm{B}$ and up to $1.5 \mathrm{~m}$ for profile $\mathrm{C}$. The differences in thickness of the low velocity layer correlates with the differences in geophone placing on top of the alluvial sediments (profile A), buried to the transition between alluvial sediments and pulverized rock (profile B), and right on pulverized rock of the outcrop but weathered due to exposure (profile $\mathrm{C}$ ).

[30] Below the surficial layers with very steep velocity increase, the tomographic models of all profiles exhibit a further but less pronounced and less strictly followed increase in velocity with depth (Figure 8). In addition, the absolute values of velocity and the vertical gradient vary laterally. Vertical structures "finger" upward composing wedges with widths of $10 \mathrm{~m}$ (e.g., see position $-70 \mathrm{~m}$, Figure 8a) to a few tens of meters (e.g., $-200 \mathrm{~m}$ and $-120 \mathrm{~m})$. The highest velocities of $>2500 \mathrm{~m} / \mathrm{s}$ are found at the cores of two of the thick vertical structures. These features stick out of the velocities of $\sim 1300 \mathrm{~m} / \mathrm{s}$ characteristic for the rocks in which they are embedded. The tomographic model for profile $\mathrm{C}$ suggests that geometrically similar lateral velocity variations, albeit associated with lower velocity values, exist even on a scale of a few meters and reach up to a depth of as little as $2 \mathrm{~m}$. 

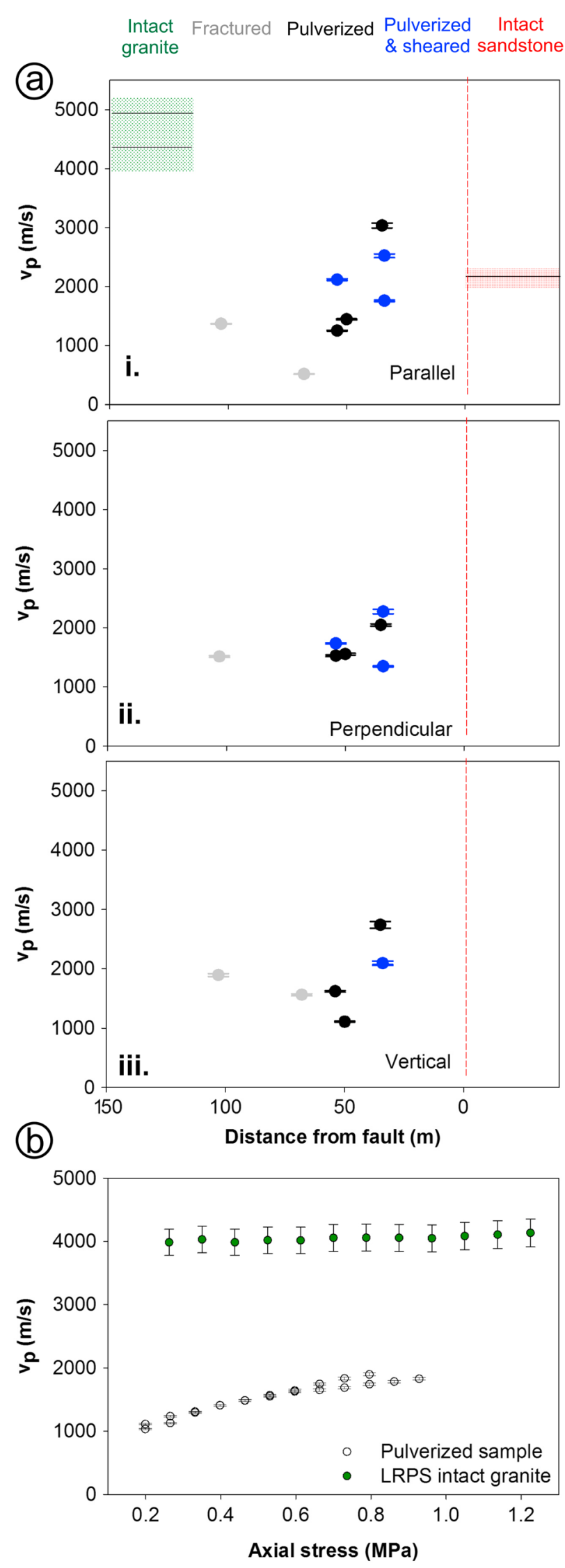

[31] At the approximate location of the long-term strand of the SAF, the modest lateral velocity contrast, with the velocity to the south of the SAF higher than to the north, may be related to its course at depth. If true also for in situ velocity relations, the coincidental similarity between velocities of sandstone and damaged granite found in the laboratory likely hinders an unequivocal imaging of the juxtaposition of the two rock types at the fault.

\section{Discussion}

[32] We described the fault zone structure, damage distribution, and textural characteristics of fault rocks of the SAF at the Littlerock Paleoseismic site, and additionally presented results of laboratory measurements of velocity and density of collected samples. Here we link these results with those from the in situ seismic measurements, put constraints on the shallow damage structure of the SAF at the Littlerock site, and address the scaling of the P-wave velocity from laboratory to field.

\subsection{Fault Damage Velocity Structure}

\subsubsection{Relating Microstructure, Velocity, and Velocity Anisotropy}

[33] The microstructural fabric of the rock samples from Littlerock site (Figures 4 to 6) shows a clear relationship to the P-wave velocities and to their anisotropy determined in the laboratory (Figure 11). Four microstructure types were distinguished according to different damage states within the granite corresponding to changes in the relationship of seismic velocities, microstructures, and anisotropy (Figure 11):

[34] 1. In the intact granite hostrock (about $-120 \mathrm{~m}$ from the SAF trace), a low apparent fracture density corresponds to generally high, nearly isotropic $\mathrm{P}$-wave velocities.

[35] 2. The velocities decrease sharply from the "intact" to the "fractured" zone $(-100 \mathrm{~m}$ to $-50 \mathrm{~m})$, corresponding to an increase in the amount of opening mode microfractures (Figures 6 and 11). The observed low velocity anisotropy with the vertical orientation showing slightly higher velocity than the horizontal directions correlates with the observed moderate preference for northwest-southeast striking (fault subparallel) microfractures, steeply dipping in a northeast direction (Figure 6).

[36] 3. The "pulverized" zone $(-50$ to $-30 \mathrm{~m})$ has slightly increased velocities (Figure 11, sample 3) with respect to the "fractured" zone despite representing significantly higher

Figure 7. (a) Laboratory ultrasonic velocities vs. distance from the fault for three orthogonal directions as indicated by the labels showing velocity anisotropy. Error bars represent experimental uncertainty for individual measurements. The symbol color corresponds to the frame color of the associated microstructure types introduced in Figure 5. The green and pink bars indicate the range of velocities measured for the two intact granite samples and the sandstone sample, respectively. While these samples are not oriented with respect to the fault the variation in velocity documents the directional dependence in three orthogonal directions. (b) Ultrasonic velocities as a function of applied axial stress for an "intact" (green symbols) and a "pulverized" sample (white symbols). 


\section{N Velocity profiles}

a) $350 \mathrm{~m}$ profile, 72 geophones, $5 \mathrm{~m}$ spacing

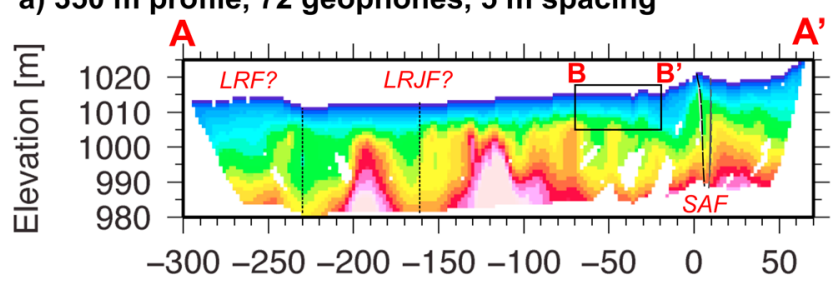

b) $50 \mathrm{~m}$ profile, 24 geophones, $2 \mathrm{~m}$ spacing

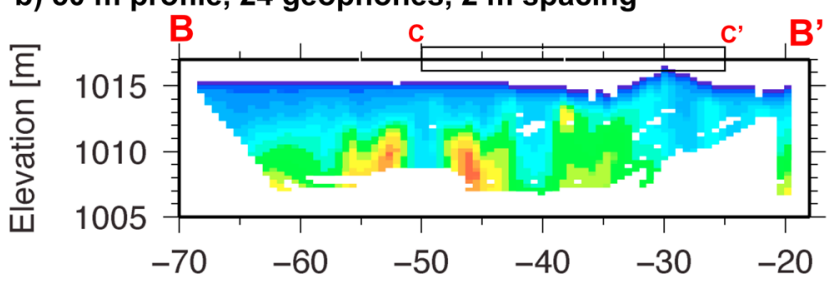

c) $25 \mathrm{~m}$ profile, 48 geophones, $0.5 \mathrm{~m}$ spacing

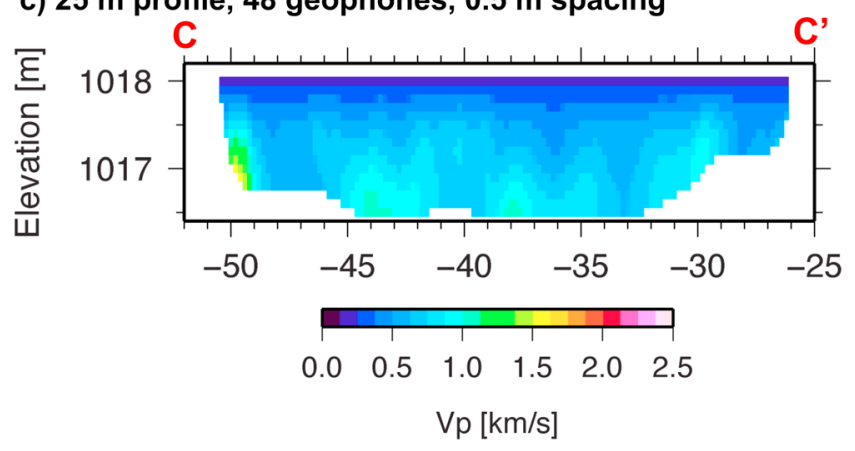

$\mathbf{S}$
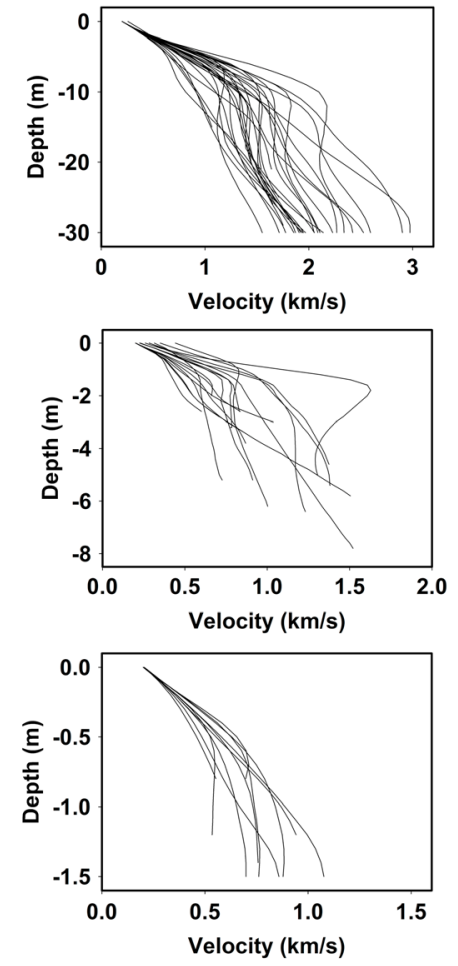

Figure 8. Velocity models gained from seismic profiles A, B, and C. The location of profile B is marked on profile $\mathrm{A}$, as is profile $\mathrm{C}$ on profile $\mathrm{B}$. X-position zero refers to the surface expression of the SAF trace. To the right of each model, velocity-depth relations (exemplary chosen for every $\sim 10, \sim 5$, and $2.5 \mathrm{~m}$, respectively) illustrate the changing velocity gradient with depth and the thickness of the low velocity top layer. All depth sections were zeroed, not showing varying elevation along the profiles but the true overburden. The vertical scale simply gives depth below surface.

levels of damage. The "pulverized" rocks closest to the transition to "pulverized and sheared" (sample 4) show a marked increase in velocity and also anisotropy. The fault-parallel orientation shows the highest velocities, the fault-perpendicular orientation the lowest. Combined with the microstructural damage observations of vertically orientated samples, these systematics indicate a preference for fault-parallel to subparallel microfractures consistent with observations on the fault-parallel and perpendicular thin sections. Subvertical fracture traces in fault-perpendicular sections, and horizontal traces with wider apparent apertures in the fault-parallel sections (Figure 6, sample 4, marked in yellow), indicate dilation preferentially accommodated by a set of fractures likely steeply dipping subparallel to the fault plane.

[37] 4. The "pulverized and sheared" zone $(-30$ to $0 \mathrm{~m}$, although the transition to "pulverized" is gradual) is characterized by intensely pulverized rock overprinted by localized shear bands. In this zone, the highest directional anisotropy in velocities is observed, with fault-normal P-wave velocities being the lowest. The anisotropy corresponds with the fault-parallel alignment of shear bands and long axes of angular fragments in a fault-parallel orientation, and additional effects of reduced grain size and effectively granular material in the subparallel shear bands, exemplified in the sample closest to the fault showing the progression to more extensive shear and comminution (Figures 6 and 11, sample 5). While the average velocity remains relatively similar to one of the other pulverized samples, velocity anisotropy is reduced, and fracture density is apparently low due to the fine-grained granular nature of the fabric. This material is closer to a gouge or ultracataclasite in terms of texture, and while still being composed of granitic minerals, it differs significantly from those recovered from the "fractured" damage zone, as shearing and compaction leads to a loss of fracture porosity. These observations, combined with localized examples of shear in core samples of pulverized rock recovered from a nearby shallow borehole by Wechsler et al. [2011], demonstrate that pulverized rocks are not necessarily homogenously microfractured, and that some anisotropic fracture patterns and shear bands develop close to the fault core.

[38] On the northeast side of the fault, the sandstone is relatively intact exhibiting no anisotropy in P-wave velocity. We did not further investigate the microstructure of the Juniper Hills sandstone in this study, however, and thus it cannot be ruled out that fault-related damage exists within these rocks. 

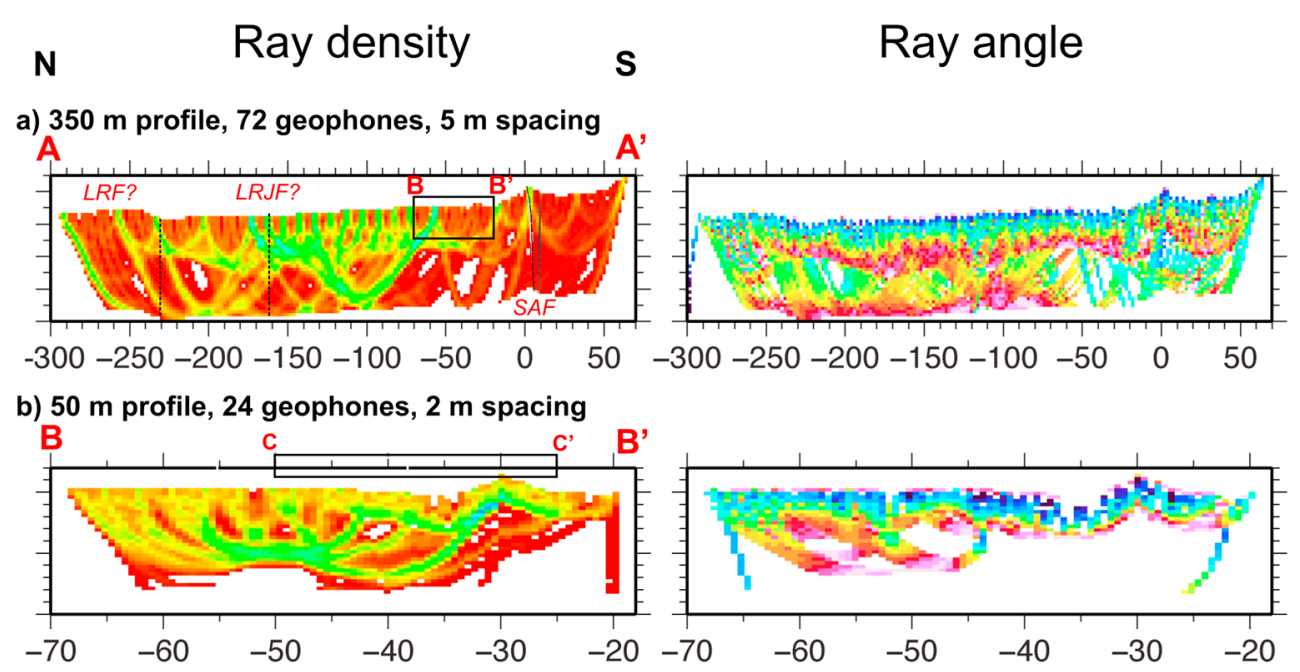

c) $25 \mathrm{~m}$ profile, 48 geophones, $0.5 \mathrm{~m}$ spacing

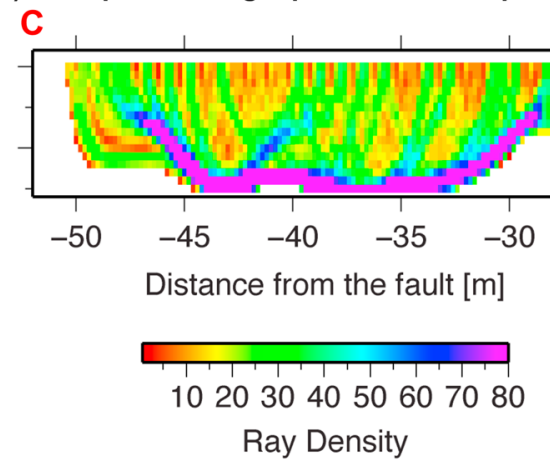

$\mathrm{C}^{\prime}$

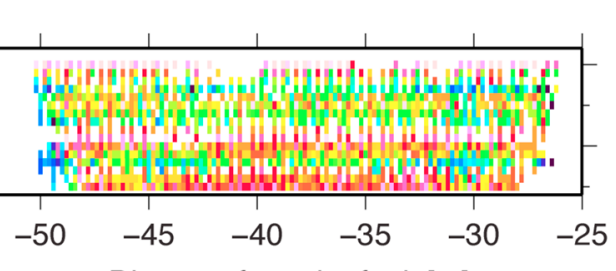

Distance from the fault [m]

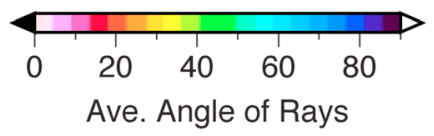

Figure 9. Resolution characteristics of the velocity models (Figure 8) represented by ray density and ray angle plots for seismic profiles A, B, and C. For the models representing profiles A and B, surface layers are dominantly sampled by "vertical" paths. Below the surface layer horizontal paths tend to dominate. The ray angle plot for the short profile $\mathrm{C}$ does not indicate a dominance of travel direction.

[39] The trend of increasing velocity with increasing damage, if not an artifact of sampling, is somewhat counterintuitive, and may be related to a faster reduction of mass density than elastic moduli with increasing fracture density or a complex interplay between the increasing number of microfractures and their width since P-wave velocities are nonunique functions of fracture density and orientation. A combination of improved density determinations and explicit microstructure modeling [e.g., Budiansky and O'Connell, 1976; Schubnel and Guéguen, 2003] could provide further insight regarding this observation.

\subsubsection{Scaling of P-Wave Velocity: From Laboratory to Field Scale}

[40] Though collected at the surface, the samples tested in the laboratory (Figure 7) yield apparently higher wave velocities than the field surveys indicate for shallow depth (Figure 8). Differences between wave velocities measured on laboratory samples and in the field are often observed [e.g., Pierre et al., 2012; Sayed, 2001; Stierman and Kovach, 1979; Taylor et al., 2011; Trippetta et al., 2010; Vinciguerra et al., 2006] and may be related to (a) bias in sampling, (b) degree of saturation with fluids, (c) dependency of elastic moduli on the duration/frequency of loading, and (d) dispersion associated with scale of structures and/or heterogeneity. Anisotropy may also contribute to differences between wave paths on different spatial scales.
[41] Despite our efforts to collect samples from the outcrops without perturbing their structure, the laboratory measurements quite likely do not represent in situ samples but are biased toward strong samples and thus higher velocities are expected from laboratory measurements than from the field survey. Since the laboratory measurements were performed on dry samples, the velocity values provide lower bounds in comparison to in situ values where at depth groundwater may be present and cause an increase in velocity. However, the seismic profiles were shot during a relatively dry summer period and thus the effect of water in the covered subsurface should not be significant.

[42] The microstructural investigations combined with the observed fairly systematic directional dependence of ultrasonic velocities of samples from the pulverized rock indicate that the damage fabrics are defined by features such as preferentially oriented microfractures, long axes of angular clasts, and bands of varying pulverization and minor shear that are orientated subparallel to the SAF. The dominant contribution to velocity estimates from a refraction survey should come from horizontal ray paths (Figure 10), and thus in situ velocities likely sample the lowest of the possible velocities according to the laboratory measurements. Therefore, anisotropy may account for some of the difference between in situ and laboratory velocities. Yet, we have no independent constraint on anisotropy for the 


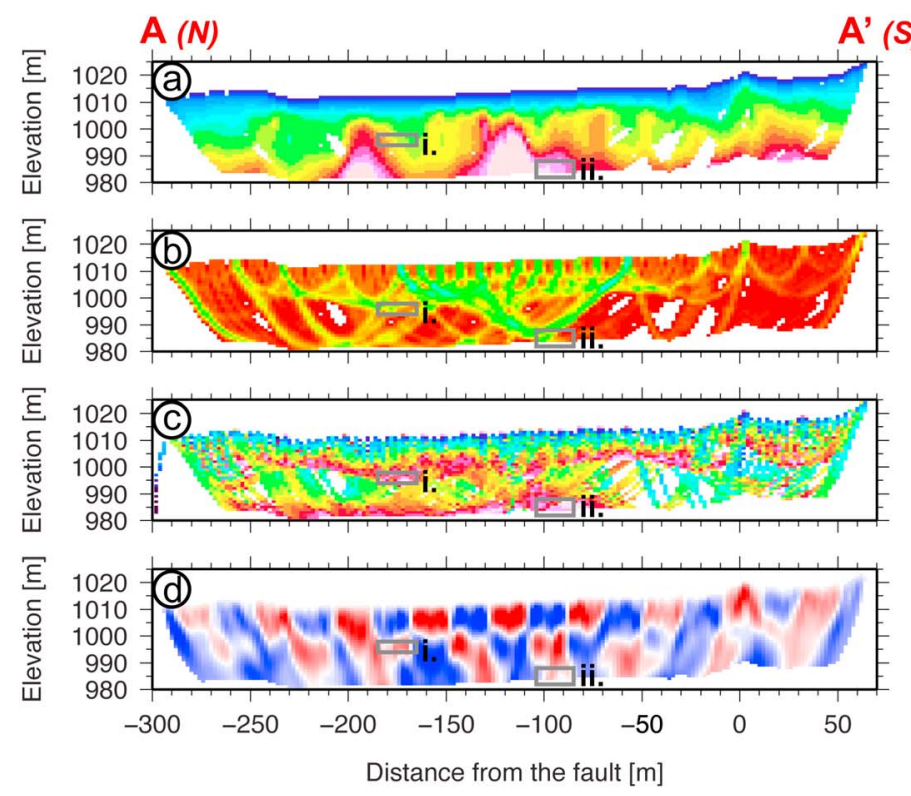

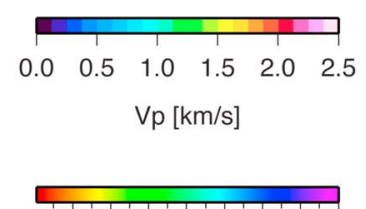

1020304050607080

Ray Density

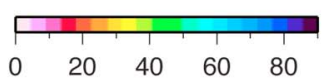

Ave. Angle of Rays

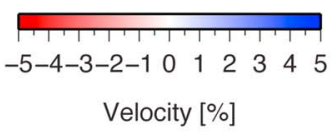

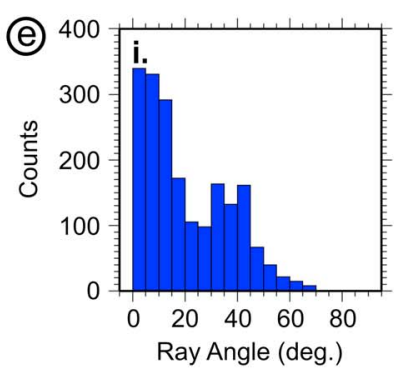

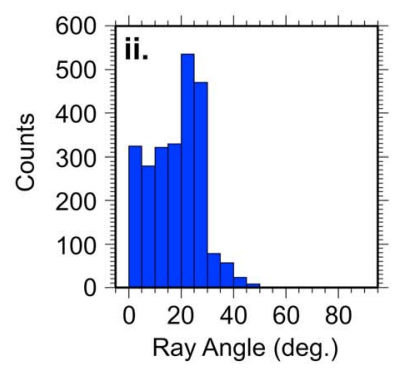

Figure 10. Comparison of (a) velocity, (b) ray density, (c) average ray angle, and (d) a checkerboard resolution test for profile A. Figure 10d shows alternating red/blue squares of the $\pm 5 \%$ amplitude perturbation that was overlaid in regions of the tomographic model that are perfectly resolved. Locations where amplitude is reduced squares are smeared indicating that the amplitude of the tomographic model is less than it should be. Results indicate good resolution down to $990 \mathrm{~m}$. (e) Histograms of ray angle for the two boxes (i) and (ii) document a large number of horizontally travelling rays that constrain the velocity. However, vertically travelling rays are also present that increase the average ray angle and thus make the model appear to lack regions of clear dominantly horizontal average angles.

field survey, and a previous study revealed that the amount of anisotropy depends strongly on the spatial scale of the measurement [Boness and Zoback, 2006]. A kilometer-scale study also revealed anisotropy for rocks surrounding the SAF that, however, was interpreted to be a relic of prefaulting fabrics [Ozacar and Zandt, 2009]. In contrast, experiments in the SAF Observatory at Depth point toward the current stress state as the dominant factor for shear velocity anisotropy in the encountered highly fractured granitic rocks [Boness and Zoback, 2006].

[43] Dispersion of wave velocities in heterogeneous or structured media is caused by high-frequency waves "finding" relatively faster paths than the ones controlling the propagation of low-frequency waves; physically, the waves of different frequencies "experience" different averages of the velocity variations [e.g., Mukerji et al., 1995; Tworzydlo and Beenakker, 2000]. The elastic waves in our field survey and laboratory experiments differ significantly in associated frequency/wavelength. For the field survey with signal frequencies below about $200 \mathrm{~Hz}$, the wavelengths exceed the meter scale, while ultrasonic signals in the hundreds of $\mathrm{kHz}$ range correspond to wavelengths of the (sub)centimeter-scale. The field data seem to constrain a trend of decreasing central frequency of first break wavelets with increasing geophone distance from the source that is actually "extended" to higher frequencies by the laboratory measurements (Figure 12). Notably, profiles $\mathrm{B}$ and $\mathrm{C}$ yield similar central frequencies of about 100 to $150 \mathrm{~Hz}$ that are consistently higher than those observed for profile A ranging between 30 and $60 \mathrm{~Hz}$. The decrease in central frequency with distance demonstrates that the subsurface material exhibits significant attenuation acting like a low pass filter. We recall that for profile A, geophones were simply pushed into the alluvial sediments covering the pulverized rocks, while for profile B, geophones were buried to a depth corresponding to the contact between alluvial sediments and pulverized rocks $(<1 \mathrm{~m})$. Profile $\mathrm{C}$ corresponds to the outcrop of pulverized rocks. Thus, the grouping of profiles with respect to frequency content of first break wavelets suggests that the alluvial sediments are responsible for the damping and that the pulverized rocks of the outcrop have similar properties as those below the alluvial sediments. If the expected dispersion for heterogeneous rocks applies to the investigated site, the increase in velocity with depth derived from the survey may be underestimated due to the increase in wavelength with increasing travel distance [see also Imhof, 2003].

[44] At face value, the difference between in situ and laboratory velocities for pulverized rocks can be largely attributed to the effect of loading (Figure 13). When applied axial loads in the laboratory and elevation in the field are taken as surrogates for overburden, field and laboratory data match in absolute values as well as their relation to depth. Note, we use the position of collected samples as an indication of what can be found in the subsurface in order to link laboratory observations and the tomographic model (Figure 11). In contrast, the difference in velocities found for "intact" granite samples in the laboratory and for subsurface regions supposedly composed of granite meet the general expectation that dispersion related with discontinuities such as fractures yields higher velocities for smaller wavelengths. While we have no direct outcrop observations for such features, joints and fractures on the meter scale are 


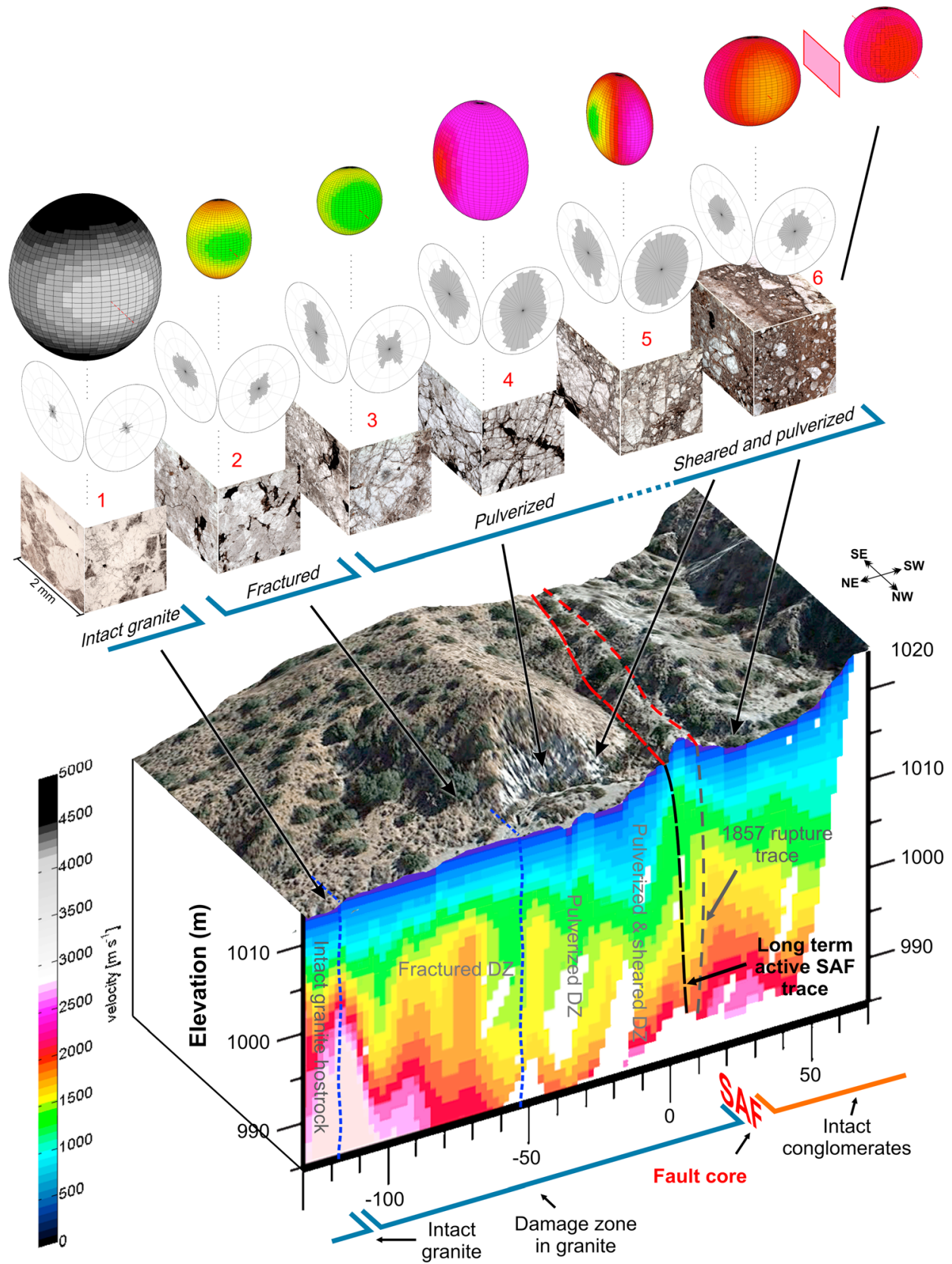

Figure 11. Summary of results from laboratory measurements, microstructure analysis and in situ seismic measurements, and the implications for different damage type zones. Ellipses, whose sizes scale with the absolute velocities (see color scheme), illustrate velocity anisotropy. They were obtained by interpolating between the three known directions. Different damage type zones inferred from laboratory velocities and microstructures transfer well to the in situ velocities.

common for granitic rocks. We cannot exclude that the agreement between laboratory and field estimates of velocities and their depth dependence for pulverized rocks represents a fortuitous combination of the various potential effects on the magnitude of velocities discussed above. However, we consider it more likely that pulverized rocks exhibit only a modest scale effect. The documented microfractures likely present the dominant structural feature affecting wave propagation on all scales. Macrofractures or other planar discontinuities on a spatial scale corresponding to the wavelength of the in situ measurements are not evidenced by the structural analysis of the outcrop. Yet, the scatter or variability of laboratory and field data suggests a volumetric heterogeneity for the pulverized rocks that may cause dispersion for wavelength exceeding the range explored here.

\subsection{Fault Zone Structure and Damage at the Littlerock Paleoseismic Site}

[45] According to our macroscopic and microstructural observations, the fault structure at the Littlerock site shows varying degrees of damage as a function of distance from the 


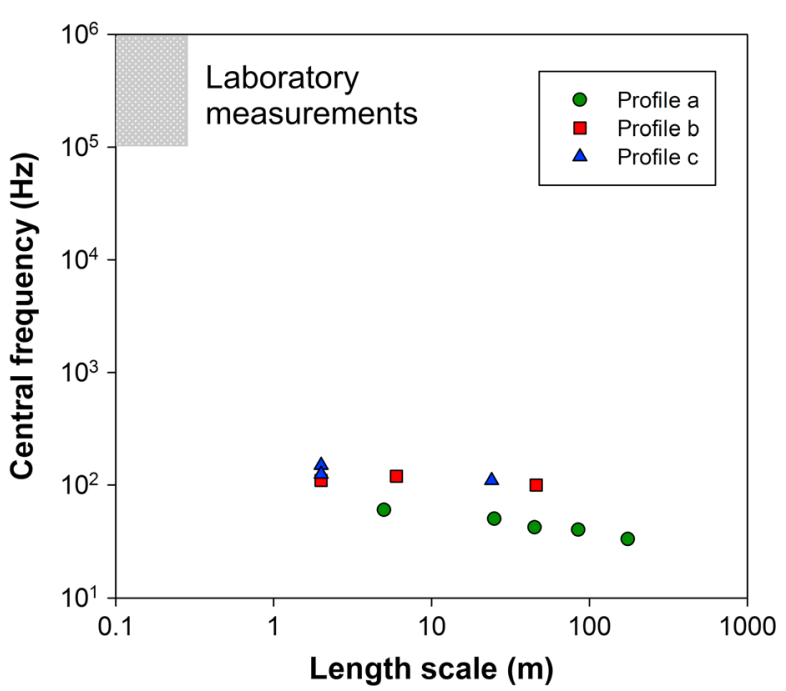

Figure 12. Central frequency of first break wavelets as a function of geophone distance from the source. Gray box shows range representative of laboratory measurements. Symbols represent individual analysis for in situ profiles A, B, and C. Central frequencies were estimated by measuring the "period" of the first break wavelets whose onset is fairly close to a harmonic function. Length scale corresponds to either sample length or distance from source as a surrogate for the distance the waves travel.

fault core. Microstructural observations define three groups of damage types, "fractured", "pulverized", and "pulverized and sheared", all of which have unique microstructures and to some extent also diagnostic velocity features (Figure 11). The fractured and the pulverized rocks constitute the damage zone within the granites, and are confined to a zone $\sim 110 \mathrm{~m}$ wide (or more) between the fault core and intact granite. Our study shows that the pulverized rock accounts for half the damage zone width on the northeastern block, followed by variably fractured rock from 50 to $100 \mathrm{~m}$ toward the outer damage zone boundary (Figure 11). At the outcrop scale, pulverized rocks of the study site show a powdered white texture when crushed in the hand, similar to samples from various other pulverized granite outcrops along the SAF, such as that of the Tejon Lookout granite in Tejon Pass [Rockwell et al., 2009; Wilson et al., 2005]. In detail, our microstructural observations combined with the observed fairly systematic directional dependence of ultrasonic velocities of samples, suggest that microfractures and shear zones are in a fault-parallel to subparallel orientation (Figures 4, 6, and 11).

[46] At the transition from "pulverized" to "pulverized and sheared" at around $30 \mathrm{~m}$ distance from the fault core, faultparallel shear bands of pulverized fabric show discrete zones of grain rotation, cataclasis, and comminution. Closer to the fault, the pulverized rock is progressively sheared, developing a stronger fault-parallel gouge-like fabric (Figure 11) farthest to the south. The inferred fault-parallel preferred orientation of microfractures and a likely low cohesive strength of the pulverized rock may have promoted more distributed fault shearing processes subparallel to the fault exploiting the weak strength and overprinting the pulverized rock, evidenced by examples of open fractures and grain boundaries being crosscut by fault-parallel shear bands. We did not investigate the main fault core, but Dor et al. [2006a] suggested that the pulverized rock in the immediate vicinity of the fault core shows macroscopic evidence of significant shear, describing the outcrop as a "proto-gouge", where the fabric and the composition are in an intermediate stage between a typical gouge and the local wall-rock. This observation, combined with that of our study on rocks $30 \mathrm{~m}$ from the fault, suggests that pulverized rocks gradually transform into more gouge-like material toward the fault core. However, while microstructural observations show offset of original grain boundaries by localized shear bands, the geological observations are inconclusive as to whether this shear occurred co-seismically or quasi-statically. Previous studies indicate that this section of the San Andreas is locked and creep is restricted to a section farther to the north [Titus et al., 2006], which might suggest a seismic origin of shear. To the south of the fault, a gradient of damage is not observable in the conglomerates. Such asymmetry is a feature commonly found for pulverized rock [Dor et al., 2006b; Dor et al., 2008; Mitchell et al., 2011].

[47] Tomography reveals that the comparatively low velocity values on the north side of the SAF strand extend over a section with a width of approximately 100 to $120 \mathrm{~m}$, where a prominent high-velocity wedge appears from depth. Based on surface observations of outcrops of intact rock at similar distances, this high velocity zone likely corresponds to subsurface intact granite. In the absence of more surface exposure, we cannot rule out that the main damage zone is

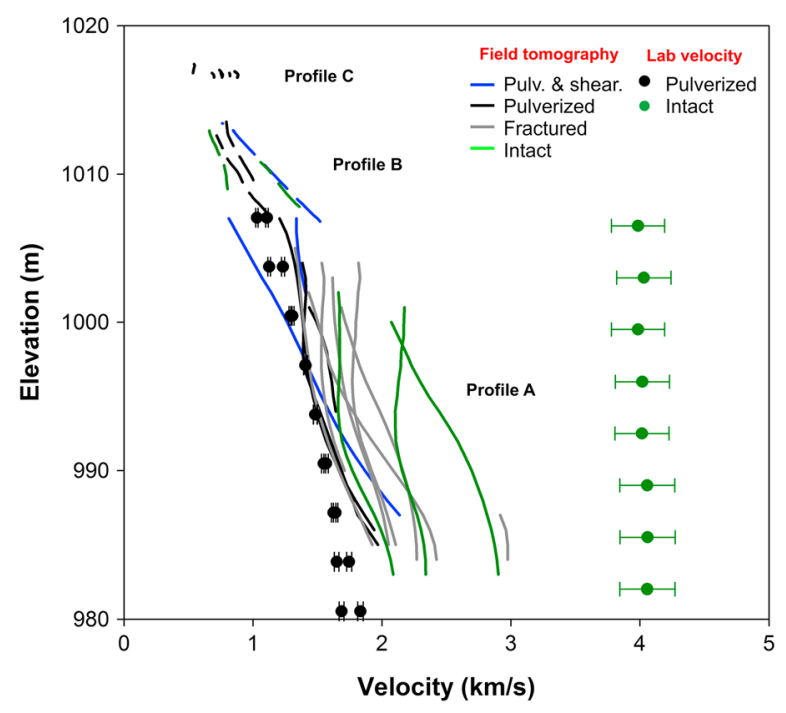

Figure 13. Comparison of $\mathrm{P}$-wave velocities from in situ (lines) and laboratory (dots) measurements. Velocity-depth relations of the tomographic models are given with the true elevation as vertical scale. Lines represent the tomographic models at every $10 \mathrm{~m}$ (profile A) and $2.5 \mathrm{~m}$ (profile B and C). The color coding of the lines is based on the microstructure classification of samples collected closest to the location of a specific depth relation. Only data below the surficial weathered layers were taken into account. For laboratory data, we (a) assumed that axial load corresponds to overburden, (b) transformed overburden to depth using average densities of 2000 and $2500 \mathrm{~kg} / \mathrm{m}^{3}$ for pulverized and intact samples, respectively, and (c) assumed that the highest elevation corresponds to zero overburden. 
complex and extends beyond $120 \mathrm{~m}$, yet we interpret the $100 \mathrm{~m}$ wide strip of relatively low velocities to reflect the width of the damage zone based on microstructural evidence that (a) damage intensity gradually decreases away from the SAF (Figure 4) and (b) the amount of damage and velocity positively correlate for a given rock type (Figure 11). The lateral spatial extension of this strip agrees well with findings of previous studies on damage zone width at other strands of the SAF, e.g., the Punchbowl fault [Chester et al., 2004; Chester et al., 1993; Chester and Logan, 1986; Chester et al., 2005; Wilson et al., 2003], which has double the displacement of the currently active strand (44 km compared to $21 \mathrm{~km}$ here). The deduced similarity in size of the damage zone for substantially different displacements fits with several existing studies that suggest a break in the scaling of damage zone thickness with displacement above a width of 100 to $150 \mathrm{~m}$ [Mitchell and Faulkner, 2009, 2012; Savage and Brodsky, 2011]. Furthermore, such damage zone thicknesses correspond to observed low velocity trapping structures for several other faults [e.g., Ben-Zion and Sammis, 2003; Lewis et al., 2005; Peng et al., 2003].

[48] The richness in lateral velocity variations from $-300 \mathrm{~m}$ to $-100 \mathrm{~m}$ in tomographic profile $\mathrm{A}$ may be related to subsidiary splay faults. The combined analyses of the geomorphology from field observations, of 1:12,000 maps of Barrows et al. [1985], and of Google Earth imagery, suggests that the Littlerock site lies within a slight bend in the fault, producing a zone of uplift (pressure ridge) to the northeast of the fault. We infer a new fault with unknown displacement called the Little Rock Junior fault (Figures $1 \mathrm{~b}$ and 1c) that corresponds well with the low velocity zone centered around $-160 \mathrm{~m}$ (Figures 1b, 1c, and 8a). In fact, several un-mapped fault traces may exist around the SAF since the sum of displacements of $160 \mathrm{~km}$ for all the faults discussed here falls short of the offset recognized for geological units of $\sim 300 \mathrm{~km}$ [Dibblee, 1989] by a factor of 2 . Farther to the north of profile A, a low velocity zone continues for $40 \mathrm{~m}$ from -210 to $-250 \mathrm{~m}$ that may well be associated with the Little Rock fault (Figure 1b), which with a total displacement of around $21 \mathrm{~km}$ might be expected to have a comparably size damage zone as the main SAF. Barrows et al. [1985] inferred its location just to the north of our study area (Figure 1b), supposedly juxtaposing shales and siltstones of the Anaverde Formation against Cretaceous granite, however the length of the inferred fault region is several kilometers long and could just as easily be inferred to cross-cut our study area. The sharp boundary of high to low velocity at $-200 \mathrm{~m}$ beneath the superficial surface cover and everything to the north may be a combination of the damage zone of the Little Rock fault and/or the lower velocity of shales and siltstones of the Anaverde Formation.

\subsection{Possible Damage Mechanisms}

[49] Our observations combined from microstructural and laboratory-derived velocity anisotropy are consistent with generation of pulverized rock by dynamic reductions in fault normal stress during fault slip [e.g., Brune, 2001], expected to produce a fault-parallel fracture orientation. The outcrop damage asymmetry of the pulverization fits with model simulations of bimaterial ruptures [Ben-Zion and Shi, 2005; Xu et al., 2012], suggesting that pulverized rocks are the cumulative product of dynamic earthquake ruptures on interfaces that separate different elastic bodies at depth. In such cases, dynamic strain fields exhibit strong asymmetry at the rupture tips propagating in the opposite along-strike directions [Adams, 1995; Andrews and Ben-Zion, 1997; Ben-Zion, 2001; Ranjith and Rice, 2001; Weertman, 1980], leading to a preferred propagation direction of ruptures and strong reduction of normal stress near the propagating tip [Ampuero and Ben-Zion, 2008; Ben-Zion and Huang, 2002; Brietzke et al., 2009; Cochard and Rice, 2000; Dalguer and Day, 2009; Shi and Ben-Zion, 2006]. For large strike-slip faults, significantly more damage is predicted to be on the side of the fault with the higher stiffness and seismic velocity at depth. In the Mojave segment of the SAF, several studies indicate that the northeastern crustal block of the SAF has the highest velocities [Fuis et al., 2003; Lutter et al., 2004; Shapiro et al., 2005], and repeating occurrences of bimaterial ruptures would therefore be expected to produce more damage on the northeast side of the SAF. This prediction agrees with the observations in this study and at many other outcrops of pulverized rocks along the Mojave segment of the SAF [Dor et al., 2006a], as well as fault zone trapped and head wave studies that indicate the existence of a shallow damage zone that is shifted toward the faster velocity side of the fault [Lewis et al., 2007; Lewis et al., 2005].

[50] If the asymmetric pulverized rocks are indeed a signature of ruptures at material interfaces, the right lateral slip at the Littlerock site would suggest a statistically preferred rupture propagation direction toward the northwest. Recent studies have generated pulverized-rock structures in experiments in axial compression at high strain rates [Doan and Billi, 2011; Doan and d'Hour, 2012; Doan and Gary, 2009; Yuan et al., 2011], suggesting that high strain-rate delocalization is another possible mechanism for generating pulverized rocks, although no predictions of fracture orientations and damage asymmetry due to this mechanism as yet exist. The results from the experiments might explain pervasive microfracture damage also seen in selected outcrops of the Juniper Hills formation sandstones to the southwest of the SAF, where the microfracture morphologies were interpreted as having formed under a state of macroscopic compression [Dor et al., 2009]. Future work should address comparisons of theoretical predictions based on experimental data on the orientation of microfracture damage from mechanisms both in compression and extension, from single and multiple overprinting events, in order to ascertain the evolving damage structure. These should include feedback processes of changing parameters after successive earthquakes such as the elastic moduli [e.g., Doan and d'Hour, 2012].

\section{Conclusions}

[51] We examined the shallow velocity structure of a strand of the SAF south of Littlerock, California by combining seismic refraction tomography, laboratory measurements of ultrasonic velocity, and microstructural observations on collected samples. At the examined location, the SAF shows a strongly asymmetric damage structure with respect to the fault core. Within the pulverized granitic rock on the northeast of the fault core, micro-scale fracture damage intensifies with increasing proximity to the fault core. The differences in 
microstructure allow us to distinguish "intact", "fractured", "pulverized", and "pulverized and sheared" fabric. Laboratory measurements of ultrasonic P-wave velocities measured on samples reflect the degree of damage and the anisotropy observed in the microstructures. A combination of microanalysis and laboratory measurements suggests that pulverized rocks closest to the fault core exhibit an anisotropic texture defined by microfractures and long axes of angular clasts with a preferred fault-parallel orientation. The three models derived from the in situ seismic measurements agree where sampling the same substratum. Below a low velocity surficial layer corresponding to weathered rock and alluvium, lateral velocity variations correlate with the width and sectioning of the damage zone inferred from microstructural analysis and laboratory velocities. While the laboratory velocities for the pulverized rocks fall into range with the in situ velocities of the damage zone, they are significantly higher for the ones of intact samples. The absence of a scaling effect for the pulverized rocks suggests a dominance of micro-scale damage, an important constraint for the interpretation of seismic data that address fault structure at a larger scale. The complex heterogeneity of the pulverized rocks in terms of damage and velocity structure should be taken into consideration when investigating fault zones at depth. The observed damage asymmetry across the fault is consistent with models of bimaterial ruptures with systematic propagation direction, as is the observed preferred fault-parallel orientation of tensile microfractures close to the fault with the related dynamic fluctuations in normal stress.

\section{Appendix A: Sample Preparation}

[52] The samples collected in the field were reoriented in the laboratory while still wrapped in tape and carefully cut to get coplanar surfaces 2 to $10 \mathrm{~cm}$ apart striking parallel and perpendicular relative to the main SAF fault trace, as well as horizontal. Water was used as coolant for the harder rocks, but the most fragile ones were cut dry. In order to minimize additional damage to the samples, the more fragile ones were first cut into several pieces, which then received only one set of oriented coplanar cuts.

\section{Appendix B: Determination of Microfracture Orientation, and Density}

[53] Two thin sections were produced for each sample oriented perpendicular and parallel to the main SAF fault trace (assumed to be approximately vertical from the tomography), with only one sample also including a horizontal cut to yield three orthogonal orientations. Analysis of fracture orientation and density was carried out by tracing fractures and grain boundaries in digital images from transmitted-light microphotographs (Figure 4). All microphotographs cover areas that are approximately $2.6 \mathrm{~mm}$ in width by $2 \mathrm{~mm}$ in height, with a resolution of 2048 by 1536 pixels. We used Griffith's et al. [2010] technique of representing traced fractures by curves composed of discrete subequal-length segments which are defined by nodes whose orientation is described by position vectors in a local reference frame. The length and orientation of each image trace were determined by measuring the orientation of each individual segment rather than by measuring a representative trend for each fracture. As discussed in Griffith et al. [2010], the two main advantages of this approach are the preservation of the inherent nonplanarity of the microfractures and the larger statistical weighting of long cracks as they are made up of more segments than shorter cracks. In order to calculate microfracture density $\Gamma$, we use a twodimensional approximation [Griffith et al., 2010] $\Gamma=$ $\sum_{i=1}^{N} a_{i}^{2} / A$, where $A$ is the total area of the traced image for which measurements were made, and $a_{i}$ is the half-length of the $i$-th microfracture. In the more pulverized samples, single fractures cannot be identified as the small size of the fragments is below the resolution of the images, and microfracture density is likely to be underestimated at the traced scale. Each rose diagram shows the orientation of fracture traces, i.e., the intersection of the fracture planes and the planes of the thin sections. To interpret the data in terms of fracture orientation in $3 \mathrm{D}$, the datasets shown in the rose diagram for each set of two orthogonal thin sections are integrated during analysis.

\section{Appendix C: Laboratory Measurement of Ultrasonic Velocity and Bulk Density}

[54] P-wave velocities were determined by ultrasonic transmission using broad-band sensors with a central frequency of $1 \mathrm{MHz}$, a pulse generator (rectangular pulse, central frequency $1 \mathrm{MHz}$, amplitude $400 \mathrm{~V}$ ), and a digital storage oscilloscope. Sensors were pressed onto the otherwise unconfined samples with a pneumatic pressure of 4.5 bar resulting in axial stresses of about 0.2 to $0.6 \mathrm{MPa}$ in the direction of wave propagation roughly corresponding to the overburden stress prevailing at the depth ranges of the tomographic profiles. To ensure a reproducible coupling of the sensors on the rough sample surfaces, silicon foils ( $<1 \mathrm{~mm}$ thickness) were placed between sample and sensors. Seismograms representing stacks of 1024 individual time series were digitally recorded. The first onset of the P-wave could be determined within an error of about $0.03 \mu \mathrm{s}$. Up to three measurements were performed on a single sample in order to check for reproducibility. The repeated measurements on a single sample varied by 3 to $12 \%$ in terms of calculated velocities.

[55] Bulk density of samples was constrained using a modified wax-clod method [Blake and Hartge, 1986]. Two pads of each sample (about $1 \mathrm{~cm}^{3}$ in size) were dried, weighed, and afterward covered in silicon paste (RTV/HV $40 \mathrm{~S}$, GLOREX GmbH). The sealed sample was weighed again, and the volume of the silicon coat was estimated from the weight difference and the density of the silicon of 1300 to $1500 \mathrm{~kg} / \mathrm{m}^{3}$ at $20^{\circ} \mathrm{C}$. The volume of the sealed pads was then determined by Archimedes' method. Bulk sample density was finally calculated from dry mass and corrected volume. The values for the two pads of each sample were averaged, the variation ranging between 0.2 and $7.4 \%$.

[56] Acknowledgments. We used the Fast code of Colin Zelt in modeling. Generic Mapping Tool was used to generate the seismic plots. We thank Amir Allam, Yaman Özakın, Neta Wechsler, Jessica Donovan, Shiqing $\mathrm{Xu}$, and David Okaya for field assistance. Mandy Duda and Ashley Griffith are thanked for assistance with MATLAB scripts, and Frank Bettenstedt for technical assistance. Ory Dor is thanked for trench photos in Figure 2. Laura Fischer is thanked for contributing velocity measurements. The paper benefited from constructive comments by Andrea Billi and Bob Holdsworth. MR, TMM, and JR acknowledge funding by the German Science Foundation (SFB 526). 


\section{References}

Adams, G. G. (1995), Self-excited oscillations of two elastic half-spaces sliding with a constant coefficient of friction, J. Appl. Mech-T. Asme., $62,867-872$.

Agosta, F., and A. Aydin (2006), Architecture and deformation mechanism of a basin-bounding normal fault in Mesozoic platform carbonates, central Italy, J. Struct. Geol., 28, 1445-1467.

Ampuero, J. P., and Y. Ben-Zion (2008), Cracks, pulses and macroscopic asymmetry of dynamic rupture on a bimaterial interface with velocityweakening friction, Geophys. J. Int., 173, 674-692.

Andrews, D. J., and Y. Ben-Zion (1997), Wrinkle-like slip pulse on a fault between different materials, J. Geophys. Res-Sol. Ea., 102, 553-571.

Barrows, A. G., J. E. Kahle, D. J. Beeby (1985) Earthquake hazards and tectonic history of the San Andreas fault zone, Los Angeles County, California. California Division of Mines and Geology Open-File Report 85-10LA, 139 p., scale 1:12,000.

Ben-Zion, Y. (2001), Dynamic ruptures in recent models of earthquake faults, J. Mech. Phys. Solids, 49, 2209-2244.

Ben-Zion, Y., and Y. Huang (2002), Dynamic rupture on an interface between a compliant fault zone layer and a stiffer surrounding solid, J. Geophys. Res. 107(B2), 2042, doi:10.1029/2001JB000254.

Ben-Zion, Y., and C. G. Sammis (2003), Characterization of fault zones, Pure Appl. Geophys., 160, 677-715.

Ben-Zion, Y., and Z. Q. Shi (2005), Dynamic rupture on a material interface with spontaneous generation of plastic strain in the bulk, Earth and Planet. Sci. Lett., 236, 486-496.

Bevington, P. R. (1969), Data Reduction and Error Analysis for the Physical Sciences, p. 320, McGraw-Hill, New York.

Billi, A., G. Di Toro (2008) Fault-related carbonate rocks and earthquake indicators: recent advances and future trends, in Structural Geology: New Research, edited by S. J. Landowe and G.M. Hammler, pp. 63-86, Nova Science Publishers, New York, ISBN: 978-1-60456-827-1.

Blake, G. R., and K. H. Hartge (1986), Bulk density, in Methods of Soil Analysis, Part I. Physical and Mineralogical Methods: Agronomy Monograph no. 9 (2nd ed.), edited by A. Klute, pp. 363-375

Blenkinsop, T. G. (1991), Cataclasis and processes of particle-size reduction, Pure Appl. Geophys., 136, 59-86.

Boness, N. L., and M. D. Zoback (2006), A multiscale study of the mechanisms controlling shear velocity anisotropy in the San Andreas Fault Observatory at Depth, Geophysics, 71, F131-F146.

Brietzke, G. B., A. Cochard, and H. Igel (2009), Importance of bimaterial interfaces for earthquake dynamics and strong ground motion, Geophys. J. Int., 178, 921-938.

Brune, J. N. (2001) Fault normal dynamic loading and unloading: an explanation for "non-gouge" rock powder and lack of fault-parallel shear bands along the San Andreas fault. EOS Trans. Am. Geophys. Union, 82, Abstract.

Budiansky, B., and R. J. O'Connell (1976), Elastic-Moduli of a Cracked Solid, Int. J. Solids Struct., 12, 81-97.

Chester, F. M., J. S. Chester, D. L. Kirschner, S. E. Schulz, and J. P. Evans (2004), Structure of large-displacement, strike-slip fault zones in the brittle continental crust, in Rheology and Deformation in the Lithosphere at Continental Margins, edited by G. D. Karner, B. Taylor, N. W. Driscoll and D. L. Kohlstedt, chap. 8, pp. 223-260, Columbia Univ. Press, New York.

Chester, F. M., J. P. Evans, and R. L. Biegel (1993), Internal Structure and Weakening Mechanisms of the San-Andreas Fault, J. Geophys. Res., 98(B1), 771-786.

Chester, F. M., and J. M. Logan (1986), Implications for mechanicalproperties of brittle faults from observations of the punchbowl fault zone, California, Pure Appl. Geophys., 124, 79-106.

Chester, J. S., F. M. Chester, and A. K. Kronenberg (2005), Fracture surface energy of the Punchbowl fault, San Andreas system, Nature, 437, 133-136.

Cochard, A., and J. R. Rice (2000), Fault rupture between dissimilar materials: Ill-posedness, regularization, and slip-pulse response, J. Geophys. Res., 105, 25891-25907.

Dalguer, L. A., and S. M. Day (2009), Asymmetric rupture of large aspectratio faults at bimaterial interface in 3D, Geophys. Res. Lett., 36, L23307, doi:10.1029/2009GL040303.

Di Toro, G., S. Nielsen, and G. Pennacchioni (2005), Earthquake rupture dynamics frozen in exhumed ancient faults, Nature, 436, 1009-1012.

Dibblee, T.W., Jr. (1989) The San Andreas Fault and major rock terranes of California displaced by it and its tectonics, in Annual Field Trip Guidebook, vols. 1 and 17, edited by Baldwin, E. Joan, et al., pp. 223-275 South Coast Geological Society.

Doan, M.-L., and A. Billi (2011), High strain rate damage of Carrara marble, Geophys. Res. Lett., 38, L19302, doi:10.1029/2011GL049169.

Doan, M.-L., and V. d'Hour (2012), Effect of initial damage on rock pulverization along faults, J. Struct. Geol., 45, 113-124.
Doan, M. L., and G. Gary (2009), Rock pulverization at high strain rate near the San Andreas fault, Nat. Geosci., 2, 709-712.

Dor, O., Y. Ben-Zion, T. K. Rockwell, and J. Brune (2006a), Pulverized rocks in the Mojave section of the San Andreas Fault Zone, Earth Planet. Sci. Lett., 245, 642-654.

Dor, O., J. S. Chester, Y. Ben-Zion, J. N. Brune, and T. K. Rockwell (2009), Characterization of Damage in Sandstones along the Mojave Section of the San Andreas Fault: Implications for the Shallow Extent of Damage Generation, Pure Appl. Geophys., 166, 1747-1773.

Dor, O., T. K. Rockwell, and Y. Ben-Zion (2006b), Geological observations of damage asymmetry in the structure of the San Jacinto, San Andreas and Punchbowl faults in Southern California: A possible indicator for preferred rupture propagation direction, Pure Appl. Geophys., 163, 301-349.

Dor, O., C. Yildirim, T. K. Rockwell, Y. Ben-Zion, O. Emre, M. Sisk, and T. Y. Duman (2008), Geological and geomorphologic asymmetry across the rupture zones of the 1943 and 1944 earthquakes on the North Anatolian Fault: possible signals for preferred earthquake propagation direction, Geophys. J. Int., 173, 483-504.

Fuis, G. S., et al. (2003), Fault systems of the 1971 San Fernando and 1994 Northridge earthquakes, southern California: Relocated aftershocks and seismic images from LARSE II, Geology, 31, 171-U173.

Griffith, W. A., S. Nielsen, G. Di Toro, and S. A. F. Smith (2010), Rough faults, distributed weakening, and off-fault deformation, J. Geophys. Res., 115(B8), B08409, doi:10.1029/2009JB006925.

Imhof, M. G. (2003), Scale dependence of reflection and transmission coefficients, Geophysics, 68, 322-336.

Lewis, M. A., Y. Ben-Zion, and J. J. McGuire (2007), Imaging the deep structure of the San Andreas Fault south of Hollister with joint analysis of fault zone head and direct $\mathrm{P}$ arrivals, Geophys. J. Int., $169,1028-1042$.

Lewis, M. A., Z. Peng, Y. Ben-Zion, and F. L. Vernon (2005), Shallow seismic trapping structure in the San Jacinto fault zone near Anza, California, Geophys. J. Int., 162, 867-881.

Lutter, W. J., et al. (2004), Upper crustal structure from the Santa Monica Mountains to the Sierra Nevada, Southern California: Tomographic results from the Los Angeles Regional Seismic Experiment, phase II (LARSE II), B. Seismol. Soc. Am., 94, 619-632.

Mitchell, T. M., Y. Ben-Zion, and T. Shimamoto (2011), Pulverized fault rocks and damage asymmetry along the Arima-Takatsuki Tectonic Line, Japan, Earth Planet. Sci. Lett., 308, 284-297.

Mitchell, T. M., and D. R. Faulkner (2009), The nature and origin of off-fault damage surrounding strike-slip fault zones with a wide range of displacements: A field study from the Atacama fault system, northern Chile, J. Struct. Geol., 31, 802-816.

Mitchell, T. M., and D. R. Faulkner (2012), Toward quantifying the matrix permeability of fault damage zones in low porosity rocks, Earth Planet. Sci. Lett., 339-340, 24-31.

Morton, N., G. H. Girty, and T. K. Rockwell (2012), Fault zone architecture of the San Jacinto fault zone in Horse Canyon, southern California: A model for focused post-seismic fluid flow and heat transfer in the shallow crust, Earth Planet. Sci. Lett., 329-330, 71-83.

Mukerji, T., G. Mavko, D. Mujica, and N. Lucet (1995), Scaledependent seismic velocity in heterogeneous media, Geophysics, 60, 1222-1233.

Nesbitt, H. W., and G. M. Young (1982), Early Proterozoic climates and plate motions inferred from major element chemistry of lutites, Nature, 299, 715-717.

Ozacar, A. A., and G. Zandt (2009), Crustal structure and seismic anisotropy near the San Andreas Fault at Parkfield, California, Geophys. J. Int., 178, 1098-1104.

Peng, Z. G., Y. Ben-Zion, A. J. Michael, and L. P. Zhu (2003), Quantitative analysis of seismic fault zone waves in the rupture zone of the 1992 Landers, California, earthquake: evidence for a shallow trapping structure, Geophys. J. Int., 155, 1021-1041.

Pierre, J., Y. Guglielmi, and F. Cappa (2012), Multiscale seismic signature of a small fault zone in a carbonate reservoir: Relationships between VP imaging, fault zone architecture and cohesion, Tectonophysics, 554-557, 185-201.

Poliakov, A. N. B., R. Dmowska, and J. R. Rice (2002), Dynamic shear rupture interactions with fault bends and off-axis secondary faulting, $J$ Geophys Res-Sol Ea, 107, doi:10.1029/2001JB000572.

Powell, R. E. (1993) Balanced palinspastic reconstruction of pre-late cenozoic paleogeology, Southern California: geologic and kinematic constraints on evolution of the San Andreas fault system, in The San Andreas Fault System: Displacement, Palinspastic Reconstruction, and Geologic Evolution, edited by R. E. Powell et al., Geological Society of America Memoir. vol. 178, pp. 1-106, Boulder, Colo.

Powell, R. E., and R. J. Weldon (1992), Evolution of the San-Andreas fault, Annu. Rev. Earth Pl. Sc., 20, 431-468. 


\section{REMPE ET AL.: DAMAGE STRUCTURE OF PULVERIZED ROCKS}

Ranjith, K., and J. R. Rice (2001), Slip dynamics at an interface between dissimilar materials, J. Mech. Phys. Solids, 49, 341-361.

Rice, J. R., C. G. Sammis, and R. Parsons (2005), Off-fault secondary failure induced by a dynamic slip pulse, B. Seismol. Soc. Am., 95, 109-134.

Rockwell, T., M. Sisk, G. Girty, O. Dor, N. Wechsler, and Y. Ben-Zion (2009), Chemical and physical characteristics of pulverized Tejon Lookout granite adjacent to the San Andreas and Garlock faults: Implications for earthquake physics, Pure Appl. Geophys., 166, 1725-1746.

Ryberg, T., M. H. Weber, Z. Garfunkel, and Y. Bartov (2007), The shallow velocity structure across the Dead Sea Transform fault, Arava Valley, from seismic data, J. Geophys. Res., 112(B8), B08307, doi:10.1029/ 2006JB004563.

Savage, H. M., and E. E. Brodsky (2011), Collateral damage: Evolution with displacement of fracture distribution and secondary fault strands in fault damage zones, J. Geophys. Res., 116(B3), B03405, doi:10.1029/ 2010JB007665.

Sayed, A. Y. (2001), In Situ Compressional Wave Velocity Across an Exposed Brittle Fault Zone, Master thesis, Virginia Polytechnic Institute and State University, Va.

Schubnel, A., and Y. Guéguen (2003) Dispersion and anisotropy of elastic waves in cracked rocks, J. Geophys. Res. 108(B2), 2101, doi:10.1029/2002JB001824.

Schulz, S. E., and J. P. Evans (2000), Mesoscopic structure of the Punchbowl Fault, Southern California and the geologic and geophysical structure of active strike-slip faults, J. Struct. Geol., 22, 913-930.

Schwartz, D. P., and R. J. Weldon (1986) Late Holocene slip rate on the Mojave segment of the San Andreas fault zone, Littlerock, CA; preliminary results, EOS Trans. Am. Geophys. Union 67, Abstract.

Shapiro, N. M., M. Campillo, L. Stehly, and M. H. Ritzwoller (2005), High-resolution surface-wave tomography from ambient seismic noise, Science, 307, 1615-1618.

Shi, Z. Q., and Y. Ben-Zion (2006), Dynamic rupture on a bimaterial interface governed by slip-weakening friction, Geophys. J. Int., 165, 469-484. Stierman, D. J., and R. L. Kovach (1979), An in situ velocity study: The Stone Canyon Well, J. Geophys. Res., 84, 672-678.

Taylor, R. L., E. H. Rutter, K. H. Brodie, D. R. Faulkner, S. Nippress, A. Rietbrock, and C. Haberland (2011), Ground-truthing In-Situ Seismic Data Against Geological Data: The Carboneras Fault Zone, S.E. Spain, EGU General Assembly, Vienna, Austria.
Titus, S. J., C. DeMets, and B. Tikoff (2006), Thirty-five-year creep rates for the creeping segment of the San Andreas fault and the effects of the 2004 Parkfield earthquake: Constraints from alignment arrays, continuous global positioning system, and creepmeters, B. Seismol. Soc. Am., 96, S250-S268.

Trippetta, F., C. Collettini, S. Vinciguerra, and P. G. Meredith (2010), Laboratory measurements of the physical properties of Triassic Evaporites from Central Italy and correlation with geophysical data, Tectonophysics, 492, 121-132.

Tworzydło, J., and C. W. J. Beenakker (2000), Hierarchical model for the scale-dependent velocity of waves in random media, Phys. Rev. Lett. $85,674-676$.

Vinciguerra, S., C. Trovato, P. G. Meredith, P. M. Benson, C. Troise, and G. De Natale (2006), Understanding the seismic velocity structure of Campi Flegrei caldera (Italy): From the laboratory to the field scale, Pure Appl. Geophys., 163, 2205-2221.

Wechsler, N., E. E. Allen, T. K. Rockwell, G. Girty, J. S. Chester, and Y. Ben-Zion (2011), Characterization of pulverized granitoids in a shallow core along the San Andreas Fault, Littlerock, CA, Geophys. J. Int., 186, 401-417.

Wechsler, N., T. K. Rockwell, and Y. Ben-Zion (2009), Application of high resolution DEM data to detect rock damage from geomorphic signals along the central San Jacinto Fault, Geomorphology, 113, 82-96.

Weertman, J. (1980), Unstable slippage across a fault that separates elastic media of different elastic-constants, J. Geophys. Res., 85, 1455-1461.

Weldon, R. J., and T. E. Fumal (2005) Slip rate of the San Andreas fault near Littlerock, California, 2005 SCEC Annual Meeting, Proc. and Abstracts, XV.

Wilson, B., T. Dewers, Z. Reches, and J. Brune (2005), Particle size and energetics of gouge from earthquake rupture zones, Nature, 434, 749-752.

Wilson, J. E., J. S. Chester, and F. M. Chester (2003), Microfracture analysis of fault growth and wear processes, Punchbowl Fault, San Andreas System, California, J. Struct. Geol., 25, 1855-1873.

Xu, S., Y. Ben-Zion, and J.-P. Ampuero (2012), Properties of inelastic yielding zones generated by in-plane dynamic ruptures-II. Detailed parameter-space study, Geophys. J. Int., 191, 1343-1360.

Yuan, F. P., V. Prakash, and T. Tullis (2011), Origin of pulverized rocks during earthquake fault rupture, J. Geophys. Res., 116, doi:10.1029/2010JB007721.

Zelt, C. A., and P. J. Barton (1998), Three-dimensional seismic refraction tomography: A comparison of two methods applied to data from the Faeroe Basin, J. Geophys. Res., 103, 7187-7210. 